\title{
Mirror, mirror on the wall: Is Economics the fairest of Vietnamese social sciences and humanities?
}

Quan-Hoang Vuong a , Khanh-Linh P. Nguyen ${ }^{a, b}$, Viet-Phuong La ${ }^{a, b}$, Thu-Trang Vuong ${ }^{c}$, Manh-Tung Ho ${ }^{a, b, d}$, Minh-Hoang Nguyen ${ }^{d, b}$, Trung Tran ${ }^{\mathrm{e}}$, Hung-Hiep Pham ${ }^{\mathrm{f}}$, Manh-Cuong Nguyen ${ }^{\mathrm{g}}$, Thanh-Hang Pham ${ }^{\mathrm{h}, \mathrm{j}}$, Manh-Toan Ho ${ }^{\mathrm{a}, \mathrm{b} . *}$

${ }^{a}$ Centre for Interdisciplinary Social Research, Phenikaa University, Yen Nghia Ward, Ha Dong District, Hanoi, 100803, Vietnam

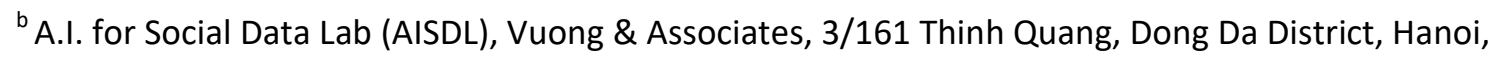
100000, Vietnam

`École Doctorale, Sciences Po Paris, 75337 Paris, France

${ }^{d}$ Ritsumeikan Asia Pacific University, Graduate School of Asia Pacific Studies, Oita Prefecture, 874-8577, Japan

${ }^{\mathrm{e}}$ Vietnam Academy for Ethnic Minorities, Hanoi 100000, Vietnam

${ }^{f}$ Center for Research and Practice in Education, Phu Xuan University, Hue 530000, Vietnam

${ }^{g}$ Faculty of International Studies, Hanoi University, Km9, Nguyen Trai Road, Thanh Xuan, Hanoi 100803, Vietnam

${ }^{\mathrm{h}}$ Faculty of Management and Tourism, Hanoi University, Km9, Nguyen Trai Road, Thanh Xuan, Hanoi 100803, Vietnam

${ }^{j}$ School of Business, RMIT Vietnam University, Hanoi, 100000, Vietnam

* Corresponding author: Manh-Toan Ho, e-mail: toan.homanh@phenikaa-uni.edu.vn

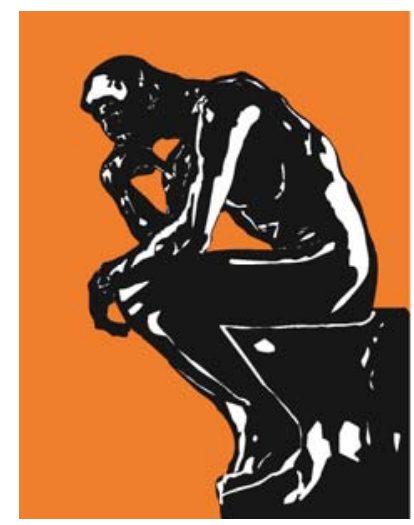

Working Paper AISDL-2005

This draft: version 10; March 6, 2020 


\begin{abstract}
As an example of a recent emerging economy, Vietnam has witnessed changes in its research policies and productivity during the last ten years. Since the establishment of the National Foundation for Science and Technology Development (NAFOSTED) in 2008, the Vietnamese scientific community had adapted to new international standards in 2014 and 2017, which resulted in different productivity between social sciences and humanities (SSH) disciplines. Therefore, to understand the effects of new research policies, this study deploys Bayesian analysis on a comprehensive dataset of 1,564 Vietnamese authors in the 2008-2018 period. The dataset was extracted from the exclusively designed Social Sciences Humanities Peer Award (SSHPA) database (http://sshpa.com/). Various factors are considered in the data collecting process, including age, gender, new authors in a year, leading authors, coauthorship, and journal's Impact Factor (JIF). The findings indicate three main characteristics of the Vietnamese SSH community after the research policy application. First, in terms of output, Economics is the dominant field relative to other SSH's disciplines in Vietnam. It has contributed 858 publications in 12 years, about two times as much as the total output of Education, the second place. Economics also experiences a high level of contribution from authors at the age of 40-44 and nearly 500 new authors within the period. Secondly, despite a rapid rise in the number of lead authors, gender disparity among disciplines is a critical issue. Male researchers outnumber female ones in Economics and Social medicine, with Education being the sole exception. Lastly, authors in Education appears to have less international collaboration than those in Social medicine, Economics, and other fields. The success of Economics could be a reference point for other SSH disciplines to increase their research output. These findings enable a better understanding of SSH research policy application and call for a more suitable policy to support female academics in a number of SSH fields.
\end{abstract}

Keywords: Social sciences and humanities; social medicine; Education; scientific productivity; research policy application; economics; SSHPA database; Vietnam. 


\section{Introduction}

Any country should have a desire to improve its scientific quality and productivity, whether it is a developed or a developing economy. Such improvement has resulted in the success of an emerging economy like China. The nation has become a scientific powerhouse, challenged the leading scientoeconomic powers, and evolved into one of the world's most considerable potentials in science (Zhou, 2009; Viglione, 2020; Abritis et al., 2017). One can say the application of a good research policy could help a country reach a higher rank in the list of world's leading scientific producers. In this case, China's strategic plans and policies to boost scientific productivity have yielded desirable results (Wu, 2019). The current situation of Vietnam shares many similarities with China 20 years ago, which is an emerging economy with an advantage of a large population. As a rising economy with a population of 97 million people, Vietnam has the potential to contribute quality publications to the international scientific community, especially having trained more than 25,000 Ph.D. holders (VNS, 2018b). Realizing the benefits of a better Social Sciences and Humanities (SSH) community, the Vietnamese government has implemented new international standards to drum up its ranking in the world scientific productivity.

From 2011 to 2017, the Vietnam National Foundation for Science and Technology Development (NAFOSTED) - the equivalent of the United States' National Science Foundation-funded 384 SSH research projects, with an average budget of VND745 million ( USD223,000) per year. Within this period, roughly one out of four funded projects belonged to the discipline of Economics (95/384) (Nafosted, 2018). Pressure on doctoral candidates and established scientists to publish can be traced to the introduction of Circular 37/2014/TT-BKHCN in 2014, which requires all national projects to result in ISI/Scopus publications (Nafosted, 2018), and Circular 08/2017/TT-BGDDT in 2017, which requires Ph.D. candidates to publish at least two articles in ISI/Scopus journals (Nguyen et al., 2019). Consequently, the number of funded projects had drastically decreased, from an average of 71 projects per year in 20112014 to only 23 projects per year in the 2015-2017 period. From these numbers, one can see that the scientific productivity of Vietnam SSH researchers was affected due to the implementation of the new policies. At the same time, the introduction of new policies might result in changes among SSH disciplines in Vietnam. This study sets out to investigate the following research question:

"How new research policies affect scientific productivity among Vietnam's SSH disciplines for the 2008-2018 period?"

To answer the question, a Bayesian analysis was applied to a dataset of publications of 1,564 Vietnamese authors in the period. The analysis will take into account three important milestones: the emergence of NAFOSTED in 2008, and the two new research policies issued in 2014 and 2017. However, first, a literature review of previous researches related to the SSH research policy application will be presented.

\section{Literature Review}




\section{Research policy and scientific productivity}

In recent years, empowered by digitalization and lower computing cost, the various effects of research policy changes have become easier to study. For example, the European Research Area (ERA), with its main task in integrating the scientific resources and programs of the European Union (EU), has created many changes in their research policies and in the way research is governed, conducted and performed across Europe since 2000 (Kastrinos, 2010). According to Kastrinos's study, SSH research plays an important subset of science, and thus the viewpoint can be illustrative of the overall national science policy scene. The European targeted to establish their market for research-funding across the board; by offering responsive-mode project funding to the best scientists, effectively forcing all national sciencefunding agencies in Europe to react to its existence. The EU aims to promote collaborative, interdisciplinary research that includes the Humanities as well as the Social Sciences (Griffin, 2006). As a result, two ERA-NET scheme projects were launched, which allowed national and regional authorities to identify research programs they wished to coordinate or opened up mutually, bringing together funding agencies from a total of 16 member states, as well as non-EU countries: Norway, Switzerland, and Canada. Both networks have been successful in launching SSH joint program with a common research budget. Then three such common programs have been launched on the themes of religions; migration; creativity and innovation; and inheritance and identity, in which participating nations have contributed more than $€ 40$ million (Kastrinos, 2010). A drawback is that the collaborations formed to capitalize funding opportunities are believed to be only effective in enhancing researcher productivity in the short run (Defazio, Lockett \& Wright, 2009).

In general, formulating research policies for SSH requires an understanding of the characteristics of research groups and individuals. Previous studies have shown that the characteristics of research groups (e.g., size and multidisciplinary) and individuals (e.g., academic status and star scientist) exerted a certain influence on scientific productivity (Olmos-Peñuela et al., 2014). A body of research about those characteristics was conducted in Western SSH study and contributed to their well-developed policies application. For instance, Lowe and Gonzalez-Brambila (2007) carried out an individual-level research measuring researchers' productivity in 15 U.S. research institutions as the number of journal articles published per year. The authors concluded that entrepreneurs are more productive than their coauthors and graduate school peers. The evidence indicated that promoting entrepreneurial faculty was worthwhile, and more support for the graduate students should be considered in the progress of revising the SSH research policy. Another study showed that university research often lacked trained younger research personnel, inadequate government research funding, and a research culture that values research activities (Harman, 2010).

The factors such as the academic level of researchers, social and cultural environment, economic and political systems are also critical to the development of social sciences research policies (Zhou, 2009). An environment in which different classes of society are encouraged to contribute to the scientific production can bring more diverse perspectives to social scientists; hence, a more critical study can be presented in the future. China, as an emerging economy, did succeed in diversifying the scientific workforce under the Maoist era (Wu, 2019). According to Wu's (2019), women, peasants, and young people are encouraged to challenge the social class and workplaces and applauded for their 
contributions to science. The World-Class University (WCU) institutions such as Perking, Tsinghua University also emphasize on attracting overseas talents for their high academic level (Yang and You, 2018). In recent years, with the rise of the Chinese economy and the government's policies of attracting talents from aboard, more voices were heard, and suggestions were given by social science researchers residing in mainland China. The nation's social science research is, thus, equally nationally and globally oriented; its research structure has been rather stable over the years (Liu, Hu, Tang \& Wang, 2015).

\section{Overview of Vietnamese SSH productivity}

Historically, Vietnamese SSH researchers have been criticized for having a rather low output, hence, a low contribution to the international academic community. Hien (2010) compared 11 East and Southeast Asian countries in terms of the total number of publications in international peer-reviewed journals per one million people, and the role of domestic researchers in peer-reviewed publications. The results showed that Vietnam was one of the countries with low performance and high dependence on international authors. Not so many Vietnamese researchers have high credibility on the world map of SSH research. Employing the Web of Science (WOS) database from 1991 to 2010, Nguyen and Pham (2011) concluded that Vietnamese authors accounted for only $6 \%$ of the total output of the Southeast Asian region. Part of the reason is due to the low quality and poor credibility of domestic scientific journals (Vu et al., 2019). A study using Scopus data found the result of Vietnamese authors' shortage as the international collaboration accounted for $77 \%$ of the country's research output (Manh, 2015). This share was reaffirmed once more using International Scientific Indexing (ISI) data in 2017 (Nguyen et al., 2017), with 90\% of Vietnamese researchers published articles as co-authors, and collaborated at least 13 times on average, mostly in a non-leading role. In summary, previous studies have highlighted the weakness of Vietnamese SSH researchers in scientific productivity, international standardize, sustainability and credibility, and the lack of proposed solutions to improve the circumstance for a long time.

One of the biggest debates when it comes to social sciences or academic publishing in Vietnam is the adoption of international scientific standards. In-depth interviews with 20 Vietnamese senior researchers in SSH suggested that they had pressures and incentives to publish in international journals (Pham and Hayden, 2019). According to the authors, Vietnamese social science researchers have several challenges in reaching world-class standards, such as language barriers, lack of awareness concerning international publishing practices, and the absence of proper incentives, whether that be financial or professional promotions. Another research found the barriers to international publication are inadequate time and lack of funding for research (Pho and Tran, 2016). The authors also showed that researchers' obstacles to international publication might vary across faculties (or disciplines), ages, qualifications, education, research, and publication experience.

For such a long time, social science and humanities scholars reportedly published more often in their mother tongue, and in journals with a limited distribution (Line, 2000). One of the reasons is because SSH research topics are sometimes more local in orientation; therefore, the target readership may be limited to a country or region, and it can be expressed and understood only by the culture that shapes them (Glänzel, 1996; Hicks, 1999; 2004; Webster, 1998). Likewise, Dr. Tran Nam Binh from RMIT University Vietnam stated that "Because of the nature of the field, social science in Vietnam is less 
globalized than hard science." (Tran et al., 2019), and many Vietnamese social scientists are still not entirely familiar with the modern format of presentation, citation, review, and methodology.

Moreover, even among scientists who have published in indexed international journals, there have been signs of its low sustainability, such as the lack of information distribution in the co-authorship network, or a high level of reliance on a few highly connected members in the networks (Ho et al., 2017). Results suggested that only specific groups such as first-authorship and seniority (age $40-50$ ) appeared to have crucial contributions in the community (Vuong et al., 2017; Vuong et al., 2018). Vuong et al. (2018) also found that authors working at research institutions had much lower scientific output than those affiliated with universities. The difference between university-researcher and institution-researcher in Vietnam is striking because the government's investment in higher education is relatively low, and higher education is still struggling between being controlled by the government and being fully autonomous (Salmi and Pham, 2019).

Fortunately, the establishment of NAFOSTED in 2008, followed by two new policies in 2014 and 2017 (Figure 1), appeared to trigger positive changes in terms of research output of SSH (Ho et al., 2017). The number of ISI-indexed publications from Vietnam thus has been rising five times since 2009 (Adams et al., 2019). Another study estimated that the publication output grew by $17 \%$ a year within the fields of SSH alone from 2008 to 2018 (Vuong, 2019b). There are some indications of international collaboration being able to increase the quality and reputation of Vietnamese science (Manh, 2015; Nguyen et al., 2017; Vuong et al., 2019). Looking into more details, some specific fields in SSH, such as Economics and Education, have increased their productivity (Vu et al., 2019; Wu, 2019).

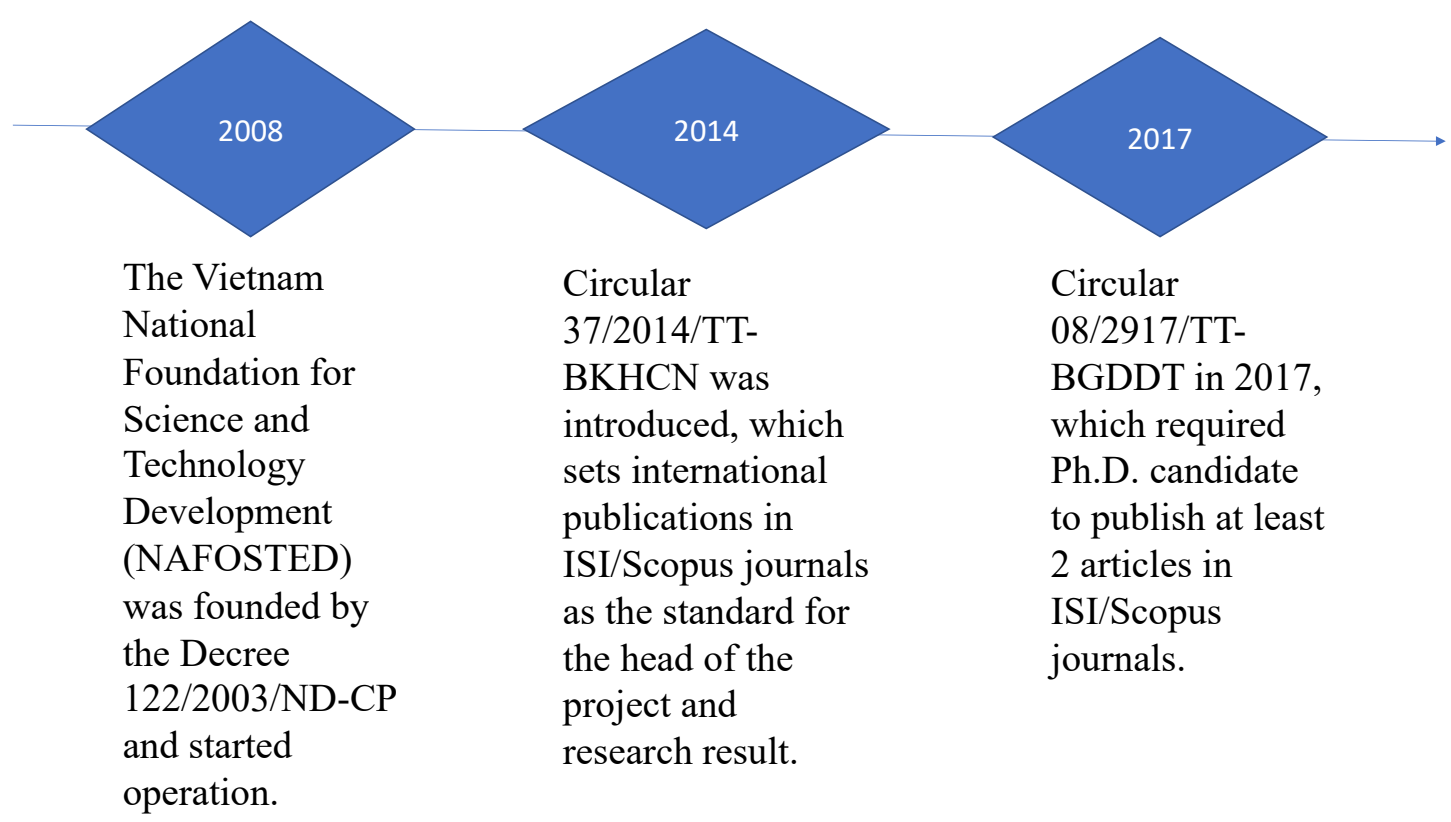

Figure 1: Timeline of main SSH research policies in Vietnam 2008-2018 
Given this background, there is a shortage of studies looking at the fine-grained details of the possible effects of new policies on different disciplines of SSH in Vietnam. Most of the previous studies looked at the macro-level picture of Vietnamese science. Hence, this paper sets out to explore the output of three major fields (Economics, Education, and Social medicine) and compare them with the rest (Others) in the period 2008-2018.

\section{Methodology}

\section{Materials and method}

A comprehensive dataset of scientific productivity of Vietnamese SSH researchers from 2008-2018 was extracted from the Social Sciences and Humanities Peer Awards (SSHPA) database, a homemade semiautomatic database that was built to record scientific productivity of Vietnamese SSH researchers. Details of the design logic and the architecture of the SSHPA database were thoroughly explained in Vuong et al. (2018)'s studies. The dataset (publicly available on GitHub: https://github.com/sshpa/bayesvl/tree/master/LectureNotes/6.SSHPA/Data) contained records of 3,238 authors, in which 1,564 are Vietnamese (854 males, 705 females, and we have not identified any author that belongs to the LGBTIQ+ group); 2,410 articles that were published in 1,171 journals (as of September 9, 2019, 23:43:01.040). The report of gender in this article follows the SAGER guidelines (Heidari et al., 2016). Using descriptive statistical analysis, four main fields were chosen to investigate the Vietnamese SSH researchers' productivity, including Economics (econ), Education (edu), Social medicine (med), and Others (others). Demographic and academic characteristics, such as age, gender, new authors, leading authors, co-authorship, and Impact Factor, were also taken into account.

Besides, the Bayesian approach was deployed for data analysis for the data about age and gender. Bayesian analysis was performed with the bayesvl package in R (La and Vuong, 2019). The bayesvl package and $\mathrm{R}$ statistical software were chosen for their potent capacity for generating graphics, diagnosing, and presenting research results from simulated data using Markov Chain Monte Carlo (MCMC) method. Moreover, the application of Bayesian statistics also aimed at improving the research process and solving the problems posed by frequentist statistics, such as the plausibility of results, the reproducibility crisis, and the controversy related to interpreting the "p-value" (Vuong, 2018).

\section{Research questions}

To answer the above research question, which is how changes in research policies affect the scientific productivity of the Vietnam SSH community in the 2008-2018 period, we aim to answer more specific questions listed in Table 1.

Table 1. Questions

\begin{tabular}{|l|l|}
\hline \multicolumn{1}{|c|}{$\begin{array}{c}\text { Characteristics of the } \\
\text { data }\end{array}$} & Questions \\
\hline Age & $\begin{array}{l}\text { - At which age do the authors have the highest productivity? } \\
\text { - Is there any difference in the age of the author in each field? }\end{array}$ \\
\hline
\end{tabular}




\begin{tabular}{|l|l|}
\hline Gender & $\begin{array}{l}\text { - Is there any gender difference between the number of publications } \\
\text { and researchers in each field? }\end{array}$ \\
\hline New Authors & $\begin{array}{l}\text { What is the difference between the age of male and female } \\
\text { researchers? }\end{array}$ \\
\hline Lead Authors & $\begin{array}{l}\text { - What are the variations in the number and the growth rate of new } \\
\text { authors across research fields from } 2008 \text { to } 2018 ?\end{array}$ \\
- $\begin{array}{l}\text { What is the average age of new researchers in each field? } \\
\text { Is there any difference in the gender of new authors in each field? }\end{array}$ \\
\hline Co-authorship & $\begin{array}{l}\text { Does the number of lead authors grow, and is there any difference } \\
\text { between the fields? }\end{array}$ \\
\hline What are the differences based on age, the gender of the lead \\
authors, in comparison with other authors?
\end{tabular}

\section{Results}

\section{Age}

\subsection{Descriptive statistics}

In SSH areas, most articles were written by researchers aged from 30 to 45 years old (444 authors). Figure 2 shows that 40 years old is the average age for researchers in each field from 2013 to 2017. After 2017, the average age has been slowly declining towards 37-38 years old. 


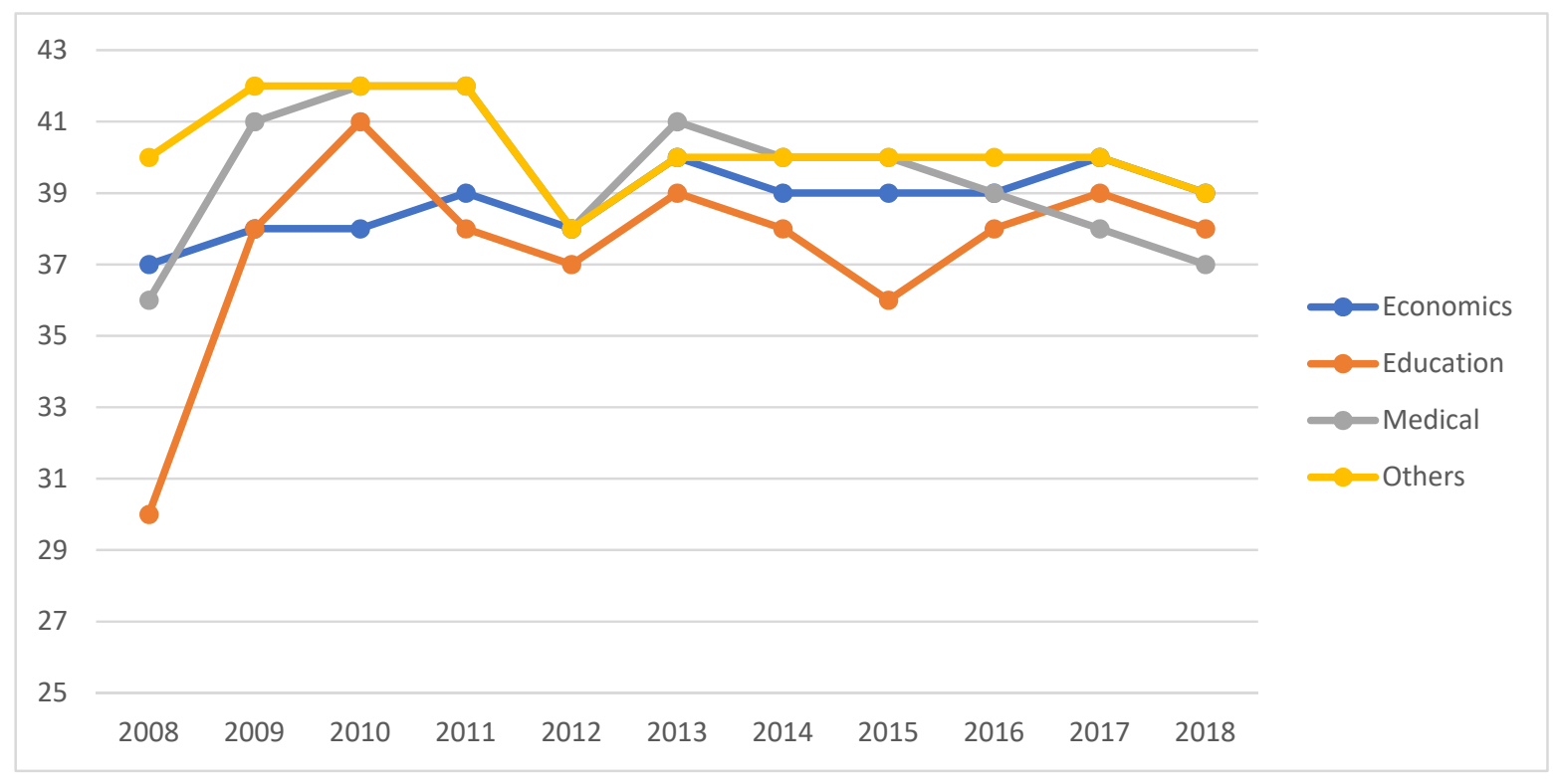

Figure 2. The average age of researchers in each field by year

Figure 3 shows the average number of publications in each age group. In Economics, Social medicine, and Others, the average number of papers all peaked when authors are in their 60s or more. Meanwhile, the productivity peak of Education researchers is in their 35-39, and then the average number slowly declines when they get older. The average output levels in Economics, Education, and Others are similar with around 2.1 articles per age group. In Social medicine, the average is higher, with 2.8 articles. In Economics (Figure 3), most of the authors under 40 have fewer publications than the average, except for the age group of 50 - 54. In Education (Figure 3), most of the age groups have similar productivity; only those of 35-39 group achieve better than average productivity.

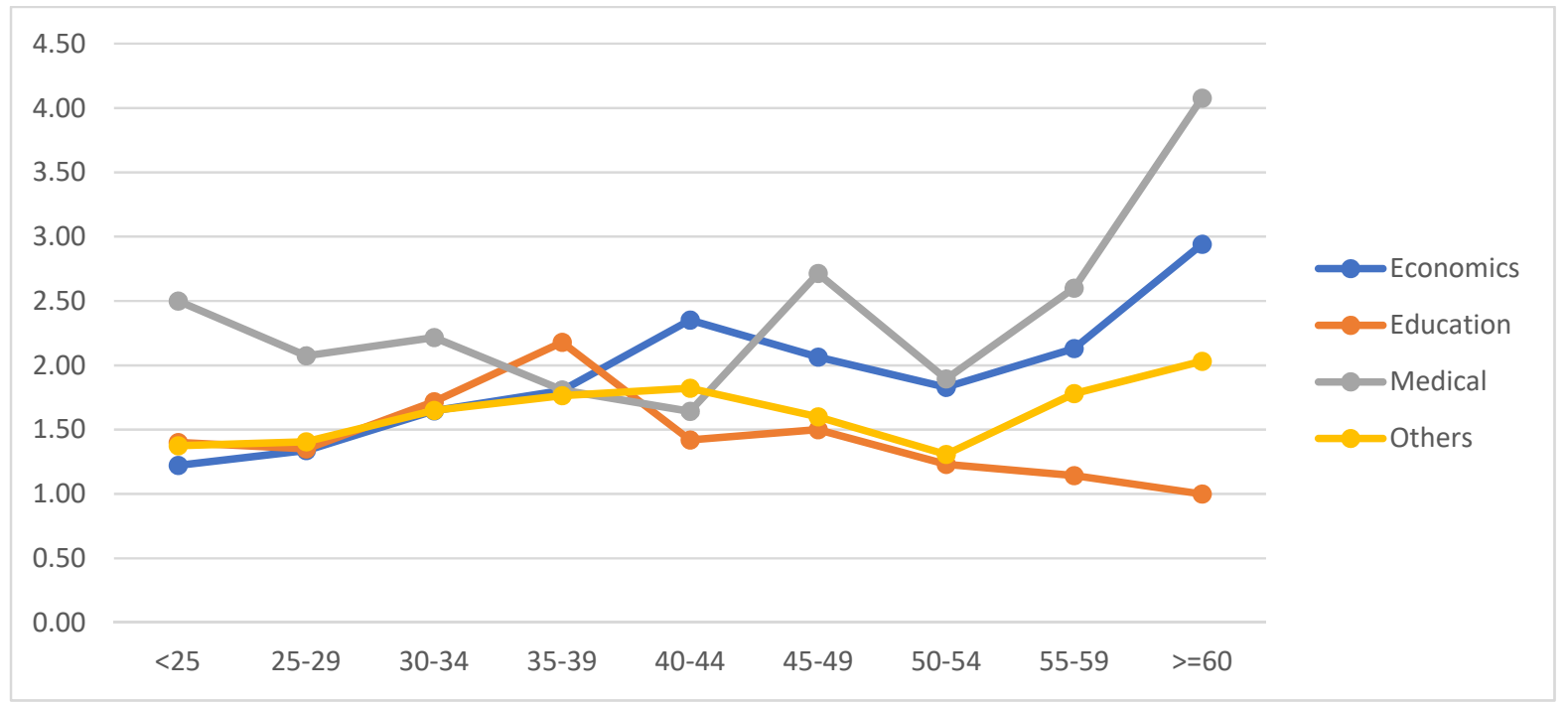


Figure 3. The average number of papers in each age group

\subsection{Bayesian analysis}

The Bayesian analytical model to determine the association between the age of authors in each field and the number of articles can be shown as:

$$
\mathrm{O}_{\text {article }} \sim \alpha_{\text {age }}\left[\alpha_{\text {field }}\right]
$$

In this model, the outcome variable $\mathrm{O}_{\text {article }}$ is the number of articles in each age group, and each field, the dependent variable $\alpha$, includes age and field, which is distributed into two layers of hierarchy. There are four levels of the variable $\alpha_{\text {field }}$ : Economics, Education, Social medicine, and Others. The variable $\alpha_{\text {age }}$ allocates authors into nine age cohorts of five years, from 25 to 60+. As there are the same numbers of age cohorts for each field, the age variable eventually has 36 levels of values ( 4 fields $\times 9$ age groups). The Stan code can be found in the Supplementary (Table S1). The result of the model simulation is as follows (Table 2):

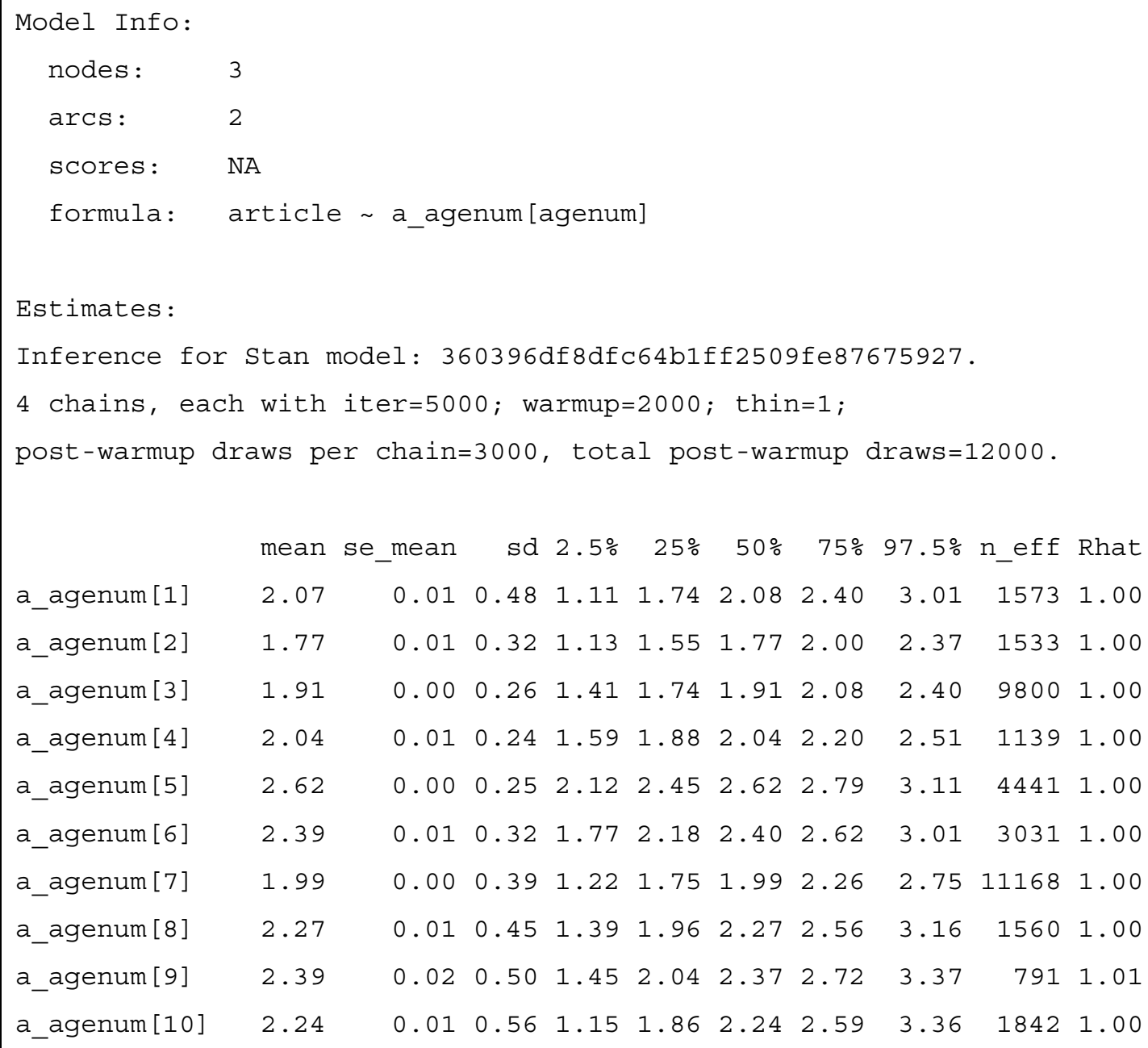




\begin{tabular}{|c|c|c|c|c|c|c|c|c|c|c|}
\hline a agenum [11] & 2.01 & 0.01 & 0.46 & 1.08 & 1.73 & 2.02 & 2.31 & 2.91 & 5140 & 1.00 \\
\hline a_agenum [12] & 1.98 & 0.02 & 0.40 & 1.22 & 1.72 & 1.97 & 2.23 & 2.82 & 274 & 1.01 \\
\hline a_agenum [13] & 2.38 & 0.02 & 0.35 & 1.71 & 2.15 & 2.38 & 2.62 & 3.05 & 375 & 1.01 \\
\hline a_agenum [14] & 1.92 & 0.01 & 0.38 & 1.17 & 1.67 & 1.92 & 2.18 & 2.64 & 2247 & 1.00 \\
\hline a_agenum [15] & 1.98 & 0.01 & 0.43 & 1.11 & 1.70 & 2.00 & 2.27 & 2.81 & 6974 & 1.00 \\
\hline a_agenum [16] & 2.03 & 0.01 & 0.50 & 0.98 & 1.69 & 2.04 & 2.37 & 2.98 & 6519 & 1.00 \\
\hline a_agenum [17] & 1.97 & 0.01 & 0.55 & 0.85 & 1.62 & 1.99 & 2.36 & 2.98 & 2336 & 1.00 \\
\hline a_agenum [18] & 2.20 & 0.01 & 0.56 & 1.05 & 1.86 & 2.19 & 2.56 & 3.29 & 10072 & 1.00 \\
\hline a_agenum [19] & 2.56 & 0.03 & 0.51 & 1.59 & 2.21 & 2.53 & 2.89 & 3.58 & 390 & 1.01 \\
\hline a_agenum [20] & 2.86 & 0.01 & 0.38 & 2.16 & 2.61 & 2.86 & 3.10 & 3.63 & 4226 & 1.00 \\
\hline a_agenum [21] & 3.24 & 0.01 & 0.39 & 2.49 & 2.97 & 3.24 & 3.50 & 4.02 & 3718 & 1.00 \\
\hline a_agenum [22] & 2.26 & 0.01 & 0.38 & 1.55 & 2.00 & 2.26 & 2.52 & 3.01 & 676 & 1.00 \\
\hline a_agenum [23] & 2.08 & 0.01 & 0.35 & 1.37 & 1.85 & 2.09 & 2.33 & 2.77 & 4480 & 1.00 \\
\hline a_agenum [24] & 3.31 & 0.01 & 0.43 & 2.48 & 3.00 & 3.30 & 3.60 & 4.19 & 2021 & 1.00 \\
\hline a_agenum [25] & 2.12 & 0.01 & 0.47 & 1.20 & 1.83 & 2.12 & 2.43 & 3.05 & 5216 & 1.00 \\
\hline a_agenum [26] & 2.67 & 0.01 & 0.50 & 1.74 & 2.33 & 2.64 & 2.99 & 3.72 & 3042 & 1.00 \\
\hline a_agenum [27] & 3.02 & 0.01 & 0.59 & 1.96 & 2.62 & 2.99 & 3.37 & 4.28 & 2823 & 1.00 \\
\hline a_agenum [28] & 2.26 & 0.01 & 0.47 & 1.33 & 1.96 & 2.26 & 2.56 & 3.20 & 8383 & 1.00 \\
\hline a_agenum [29] & 1.88 & 0.00 & 0.33 & 1.23 & 1.67 & 1.87 & 2.10 & 2.52 & 8219 & 1.00 \\
\hline a_agenum [30] & 1.92 & 0.00 & 0.24 & 1.45 & 1.76 & 1.92 & 2.08 & 2.41 & 7934 & 1.00 \\
\hline a_agenum [31] & 2.08 & 0.00 & 0.23 & 1.61 & 1.93 & 2.08 & 2.24 & 2.53 & 6191 & 1.00 \\
\hline a_agenum [32] & 2.14 & 0.01 & 0.26 & 1.66 & 1.96 & 2.14 & 2.32 & 2.66 & 1597 & 1.00 \\
\hline a_agenum [33] & 1.99 & 0.01 & 0.31 & 1.37 & 1.77 & 1.98 & 2.20 & 2.58 & 448 & 1.01 \\
\hline a_agenum [34] & 1.72 & 0.00 & 0.37 & 0.97 & 1.49 & 1.72 & 1.97 & 2.41 & 6220 & 1.00 \\
\hline a_agenum [35] & 2.35 & 0.04 & 0.44 & 1.14 & 2.09 & 2.37 & 2.64 & 3.14 & 133 & 1.02 \\
\hline a_agenum [36] & 2.22 & 0.01 & 0.42 & 1.44 & 1.93 & 2.22 & 2.51 & 3.06 & 1044 & 1.01 \\
\hline sigma_agenum & 0.55 & 0.00 & 0.14 & 0.31 & 0.45 & 0.54 & 0.64 & 0.85 & 2026 & 1.00 \\
\hline a_fieldnum [1] & 2.32 & 0.01 & 0.22 & 1.94 & 2.18 & 2.31 & 2.46 & 2.79 & 992 & 1.00 \\
\hline a_fieldnum [2] & 2.10 & 0.00 & 0.22 & 1.62 & 1.97 & 2.12 & 2.26 & 2.51 & 4999 & 1.00 \\
\hline a_fieldnum [3] & 2.32 & 0.01 & 0.21 & 1.94 & 2.18 & 2.31 & 2.45 & 2.76 & 982 & 1.00 \\
\hline a_fieldnum [4] & 2.23 & 0.00 & 0.20 & 1.83 & 2.09 & 2.23 & 2.35 & 2.63 & 3075 & 1.00 \\
\hline a0_fieldnum & 2.24 & 0.01 & 0.29 & 1.68 & 2.10 & 2.24 & 2.37 & 2.82 & 1172 & 1.00 \\
\hline sigma_fieldnum & 0.36 & 0.01 & 0.46 & 0.03 & 0.11 & 0.23 & 0.43 & 1.48 & 1584 & 1.00 \\
\hline
\end{tabular}

Table 2: The results of the simulation for the Bayesian model of age.

The visual diagnostic of MCMC chains is shown in Figure S1 in Supplementary. In Figure 4, the productivity of each field is presented. The average lines in economics, education, and others are 
similar, around 2.1 articles. In social medicine, the average is higher, with 2.8 articles. In economics (Figure 4a), most of the authors who are under 40 have fewer publications than the average (the red line), except the age group of $50-54$. The age group of $40-44$ has been leading in productivity, while the age group of under 25 is aiming to surpass the average line.

In education (Figure 4b), most of the age groups have similar productivity, only the age groups of 35 39 , older than 60 , and under 25 are achieving better the average productivity. For social medicine (Figure 4c), the $45-40$ age group is with the highest productivity, while in the others (Figure 4d), the 55 -59 has the highest productivity.

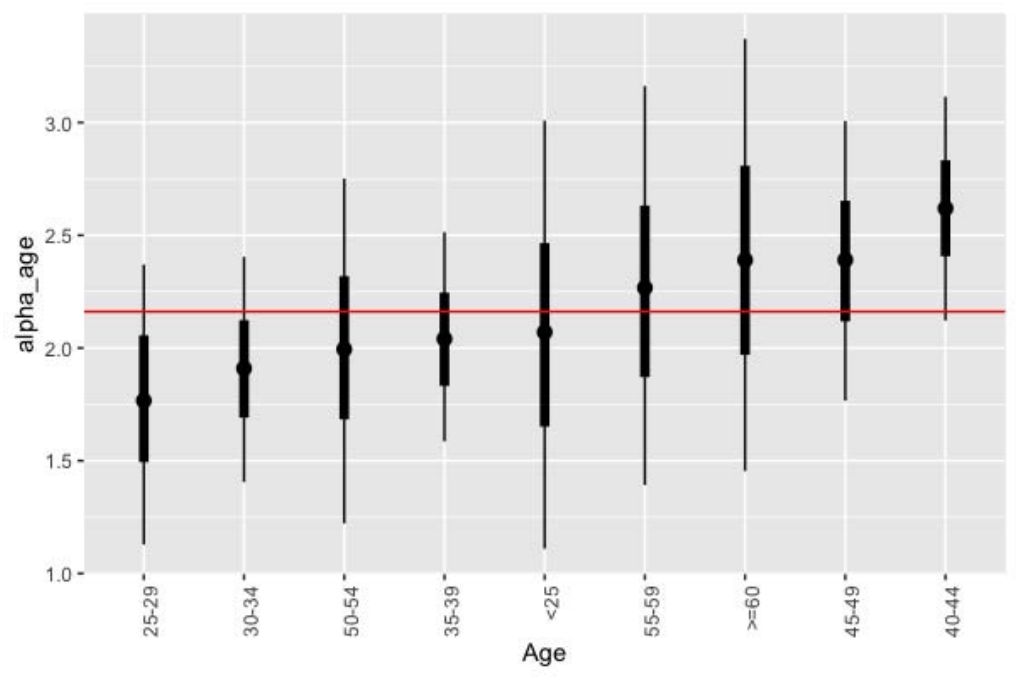

Fig 4a) Economics

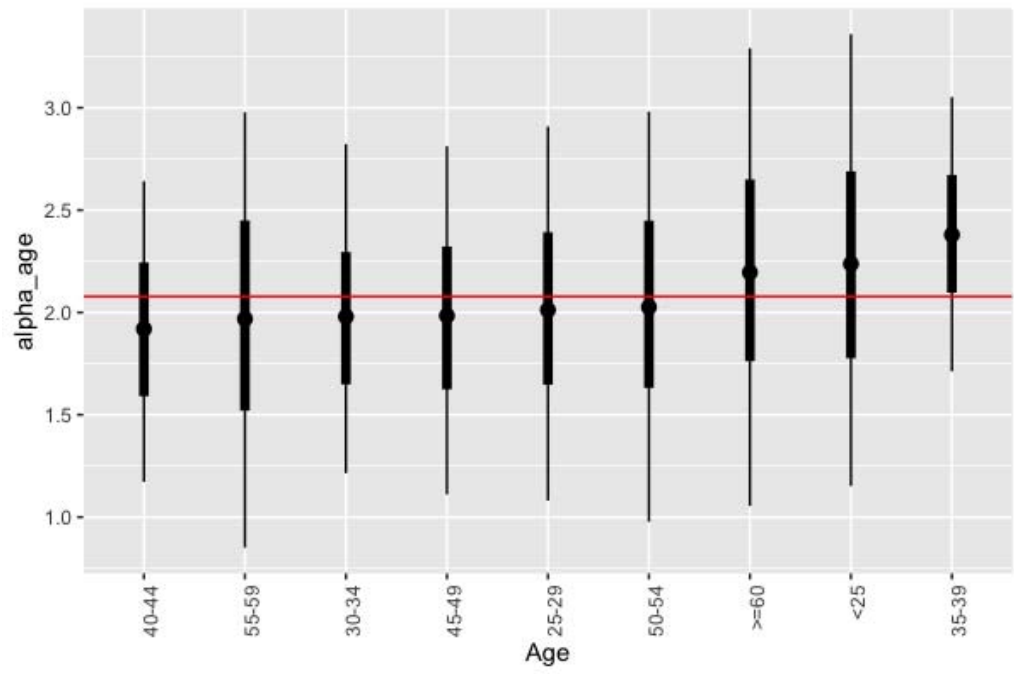

Fig 4b) Education 


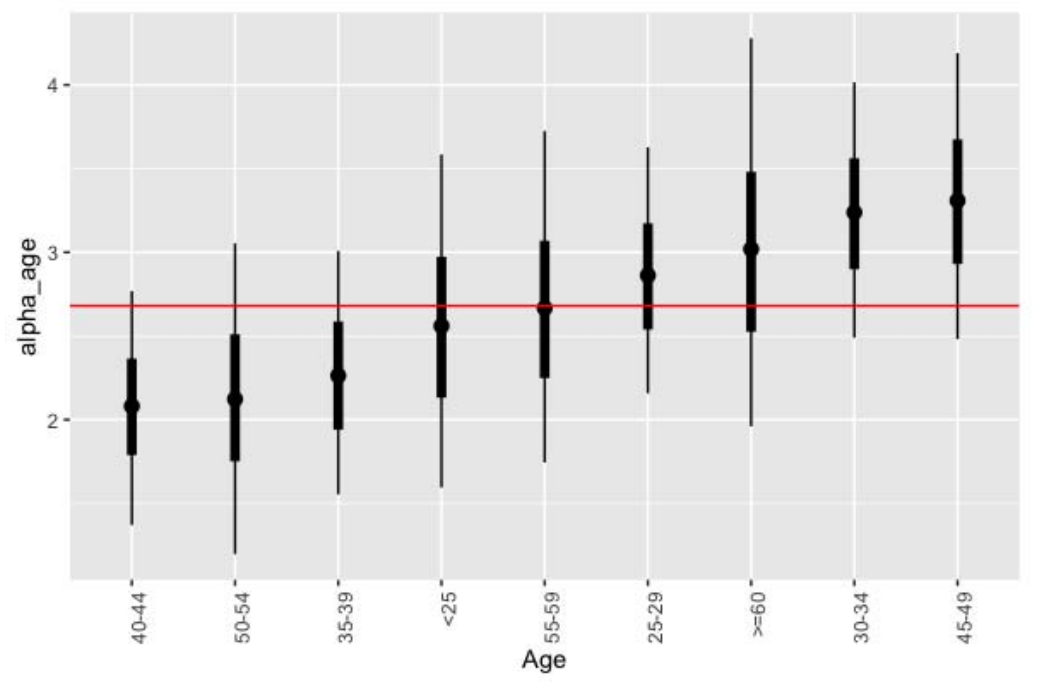

Fig 4c) Social Medicine

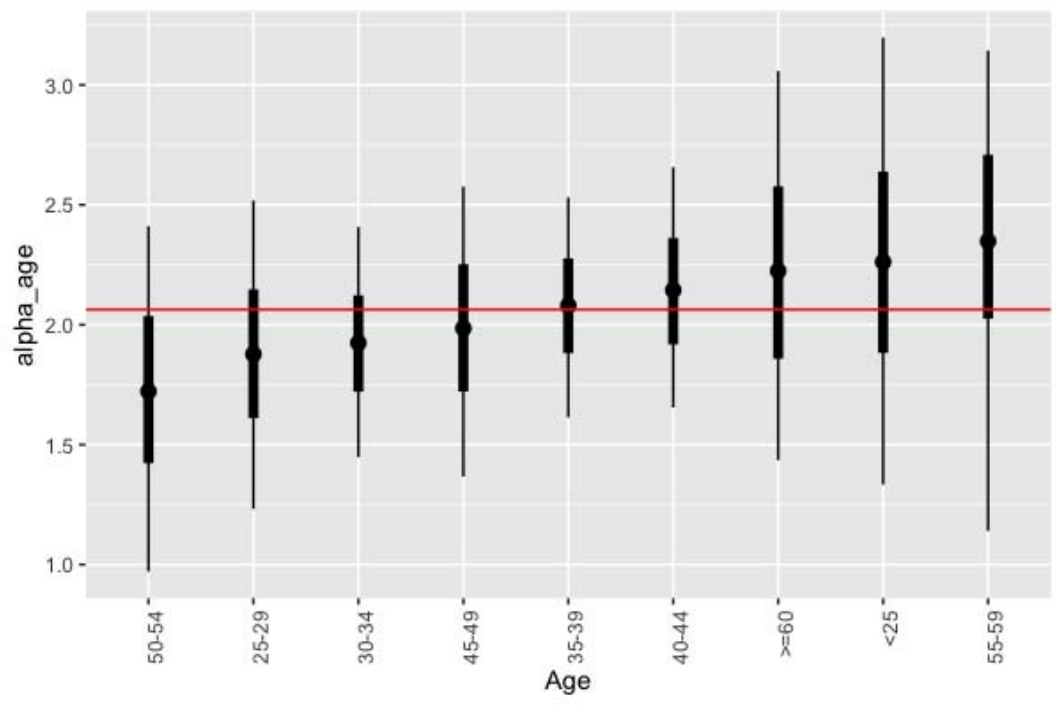

Fig 4d) Others

Figure 4. The Bayesian analysis of the productivity of researcher according to age and discipline

\section{Gender}

\subsection{Descriptive analysis}

Figures 5 and 6 show that male has a significantly high number of publications and surpasses female in Economic and Other fields. In the Medical field, there is a slightly higher number of publications by males than females, but the number of female researchers exceeds that of their male counterparts; 
therefore, Medical is the only field in which gender disparity is not observed. Interestingly, in the field of Education, female surpasses male in both the number of publications and researchers.

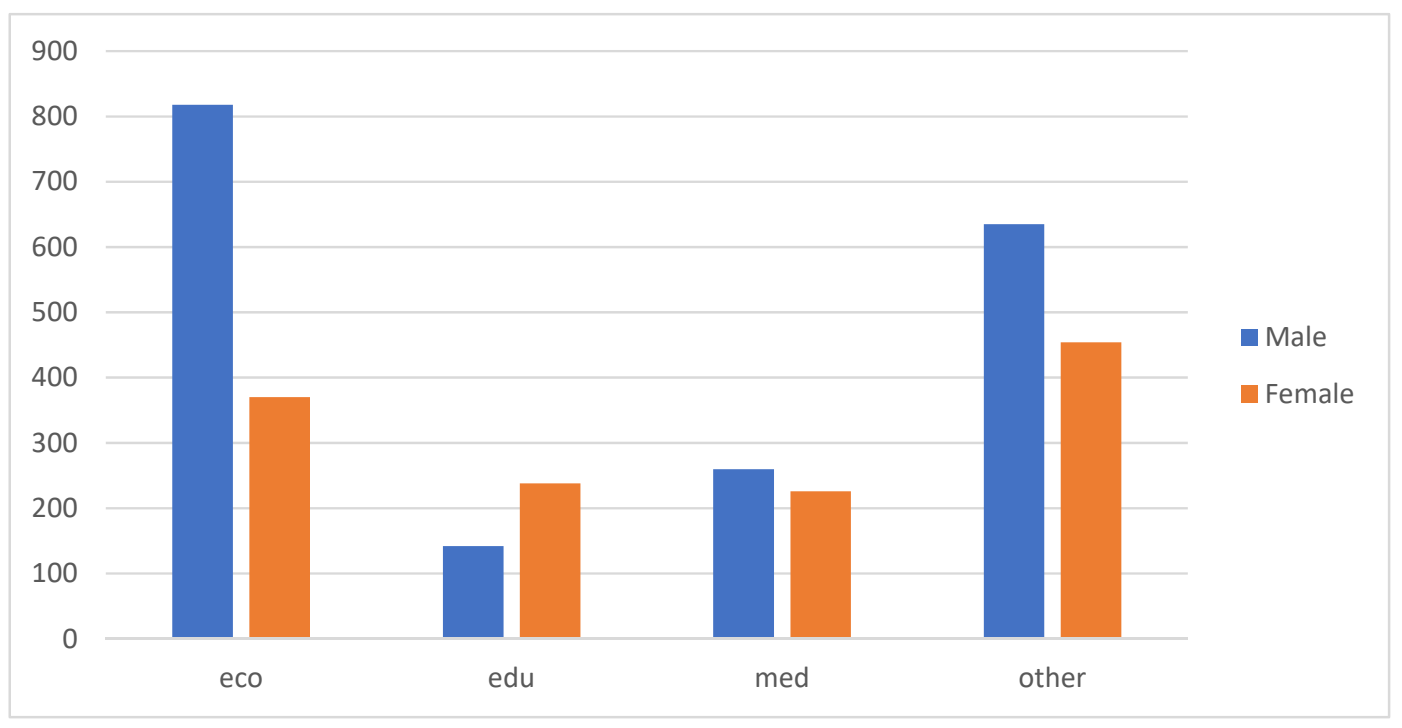

Figure 5: The total number of publications by gender and discipline

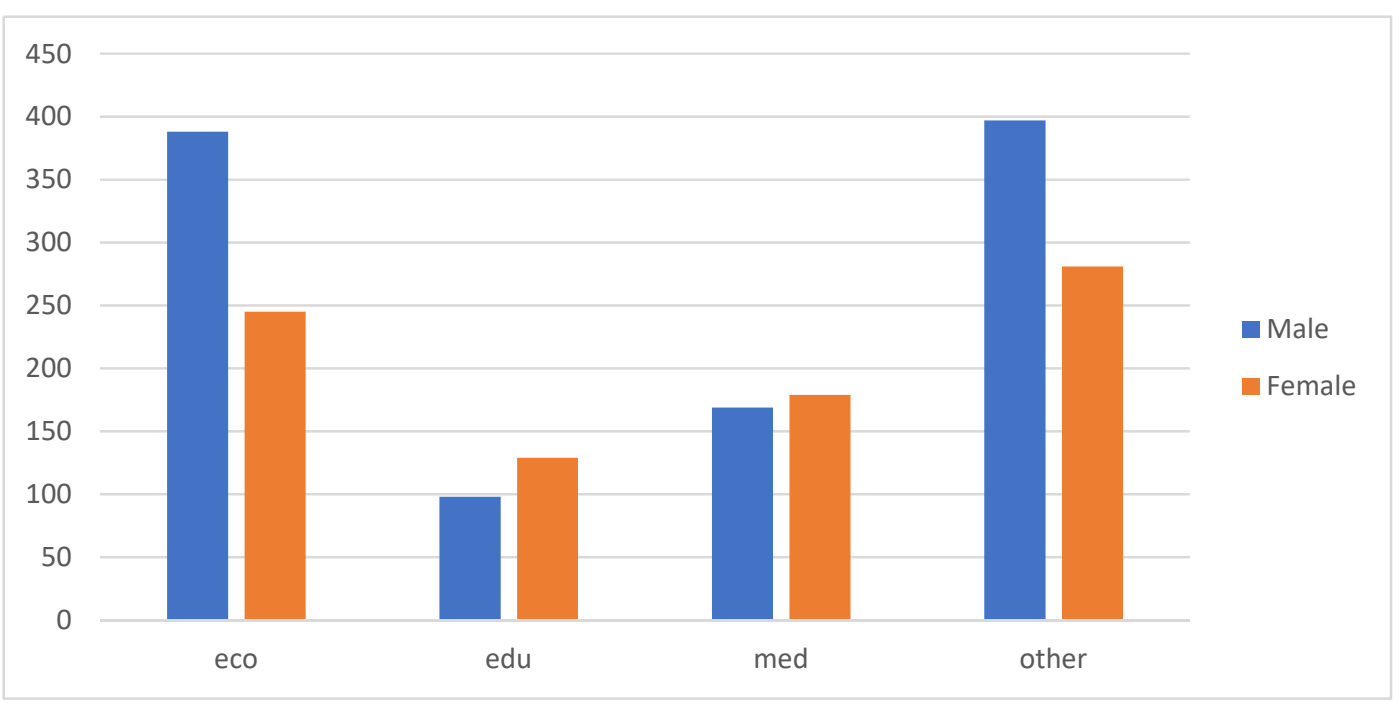

Figure 6: The number of researchers by gender and discipline

Table 3 shows that the average age of male researchers is relatively higher than that of the female. In both genders, researchers in Economics have the lowest average age, while those in Other fields have the highest average age. However, as an author can be inputted many times in the database at different ages, the difference in the average age between male and female researchers is demonstrated more clearly from the longitudinal angle. 


\begin{tabular}{|c|c|c|}
\hline Field & Male & Female \\
\hline eco & 41 & 36 \\
\hline edu & 41 & 36.8 \\
\hline med & 41.8 & 37.3 \\
\hline other & 42.4 & 37.4 \\
\hline
\end{tabular}

Table 3: Average age of male and female researchers by discipline

\subsection{Bayesian analysis}

In the Bayesian analysis, the outcome variable is the number of publications. The model consists of two independent variables of gender - "gender", and research field - "field" with two hierarchies as follows:

$$
\mathrm{O}_{\text {article }} \sim \alpha_{\text {gender }}\left[\alpha_{\text {field }}\right]
$$

The summary of the model simulation is shown in Table 3. The Stan code and the visual diagnostic of MCMC chains are available in the supplementary (Table S2, Figure S2).

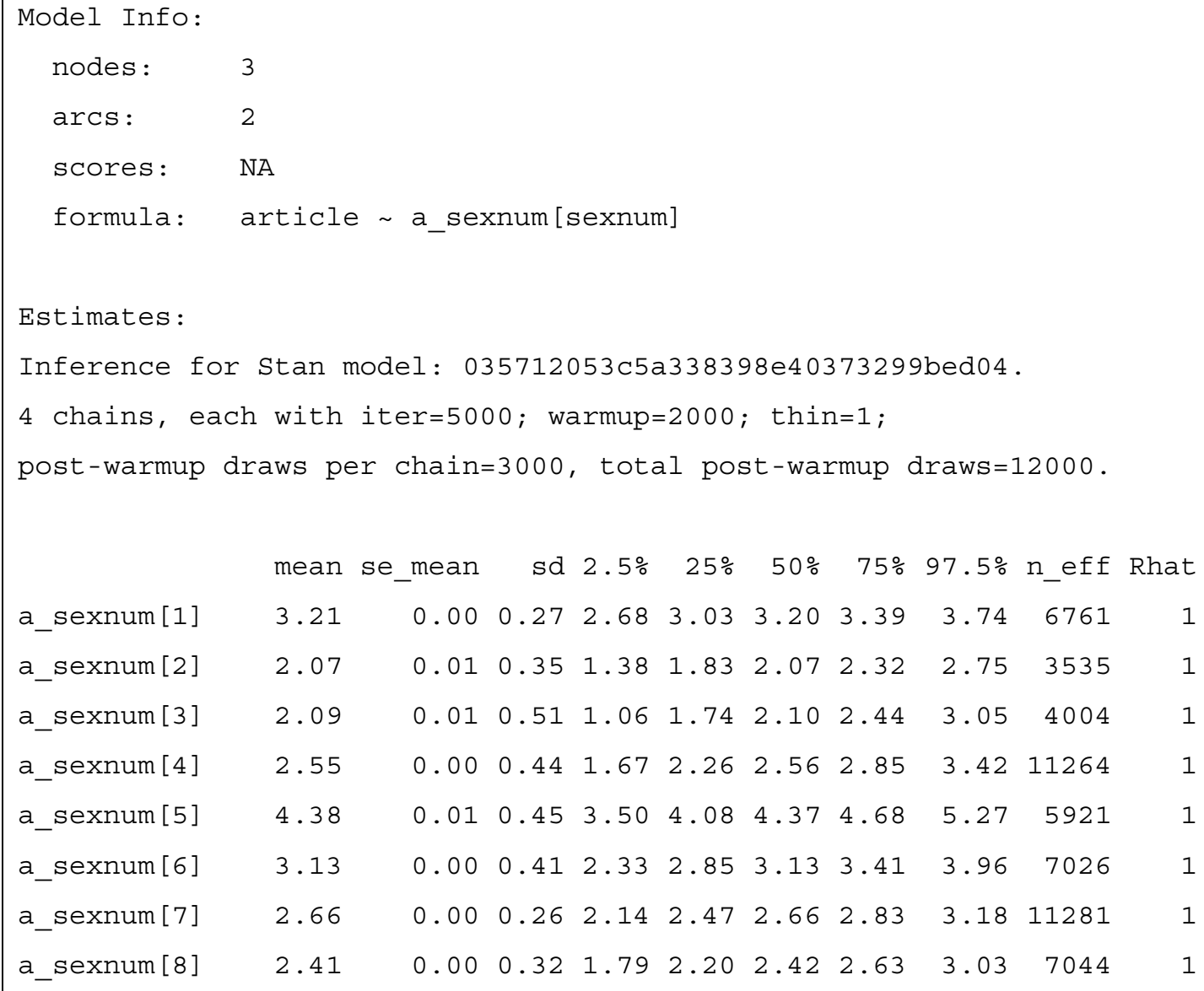




\begin{tabular}{|c|c|c|c|c|c|c|c|c|c|c|}
\hline sigma sexnum & 1.12 & 0.01 & 0.55 & 0.47 & 0.78 & 0.99 & 1.30 & 2.48 & 2103 & 1 \\
\hline a_fieldnum [1] & 2.84 & 0.01 & 0.67 & 1.49 & 2.49 & 2.85 & 3.20 & 4.18 & 5907 & 1 \\
\hline a_fieldnum [2] & 2.98 & 0.01 & 0.66 & 1.72 & 2.62 & 2.95 & 3.33 & 4.40 & 5292 & 1 \\
\hline a_fieldnum [3] & 2.79 & 0.01 & 0.70 & 1.43 & 2.45 & 2.81 & 3.13 & 4.10 & 6471 & 1 \\
\hline a_fieldnum [4] & 2.62 & 0.01 & 0.69 & 1.18 & 2.26 & 2.66 & 3.00 & 3.89 & 5216 & 1 \\
\hline a0_fieldnum & 2.80 & 0.01 & 0.83 & 1.06 & 2.46 & 2.82 & 3.16 & 4.45 & 3349 & 1 \\
\hline sigma_fieldnum & 0.92 & 0.03 & 1.16 & 0.06 & 0.26 & 0.56 & 1.11 & 4.06 & 1519 & 1 \\
\hline
\end{tabular}

Table 3: The results of the simulation for the Bayesian model of gender.

Figure 7 displays the distribution of posterior probabilities according to gender in each field. In the Economic and Medical fields, male researchers have a substantially higher probability of producing more articles than female researchers. Moreover, male researchers are more productive than female counterparts in Other fields, but the disparity is small. Only in the Educational field that female researchers have slightly higher outcomes than male researchers.

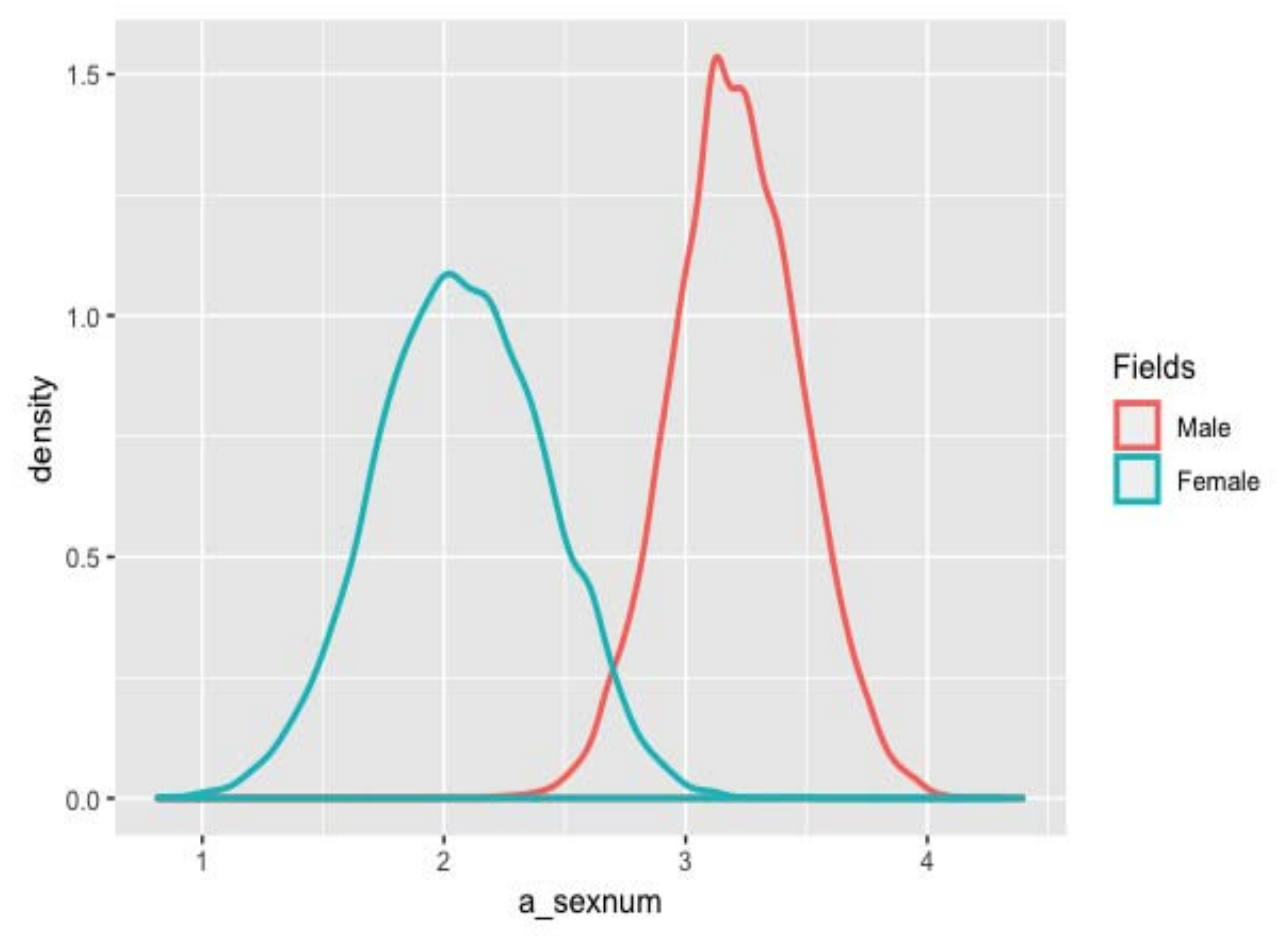

Fig 7a): Economics 


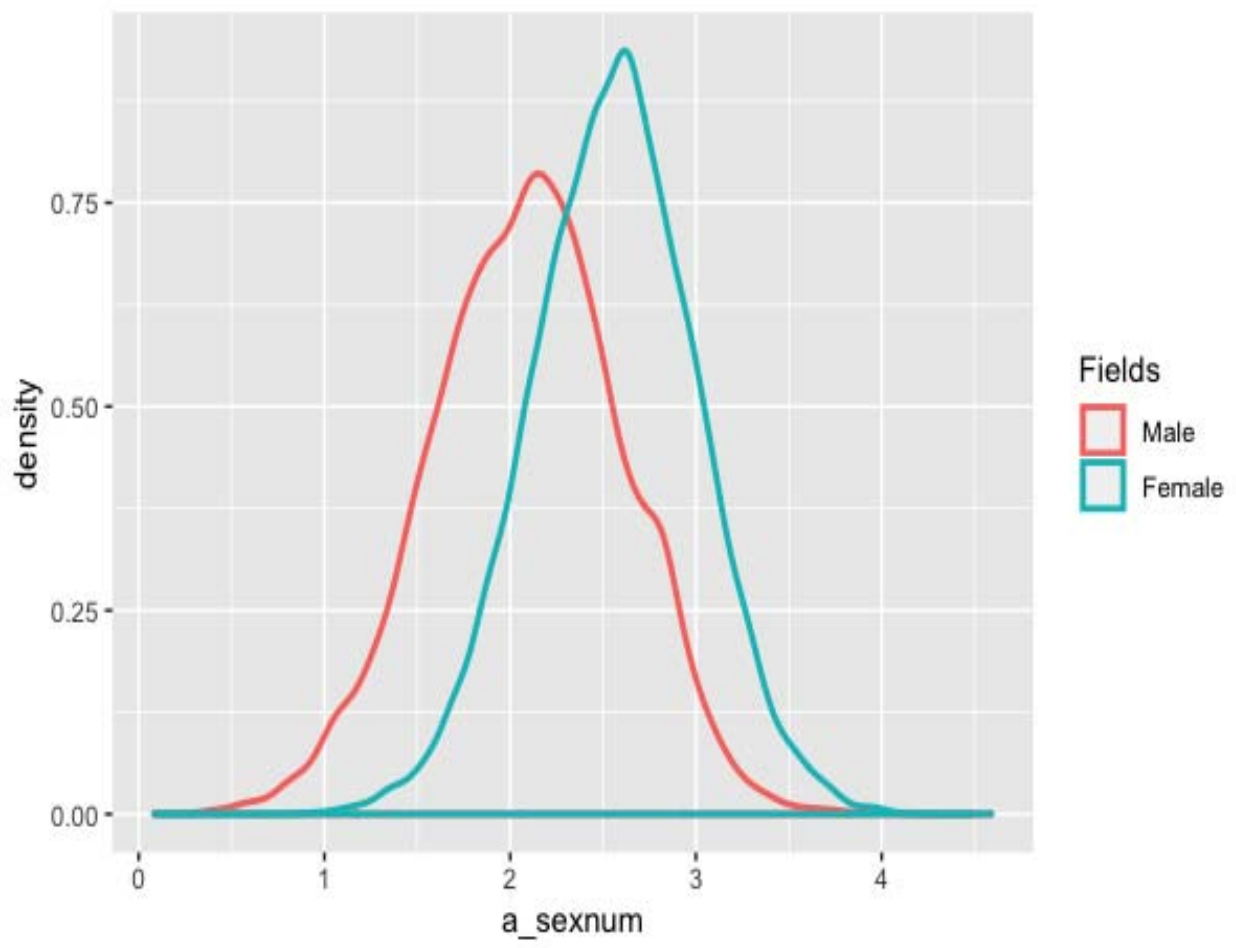

Fig 7b): Education

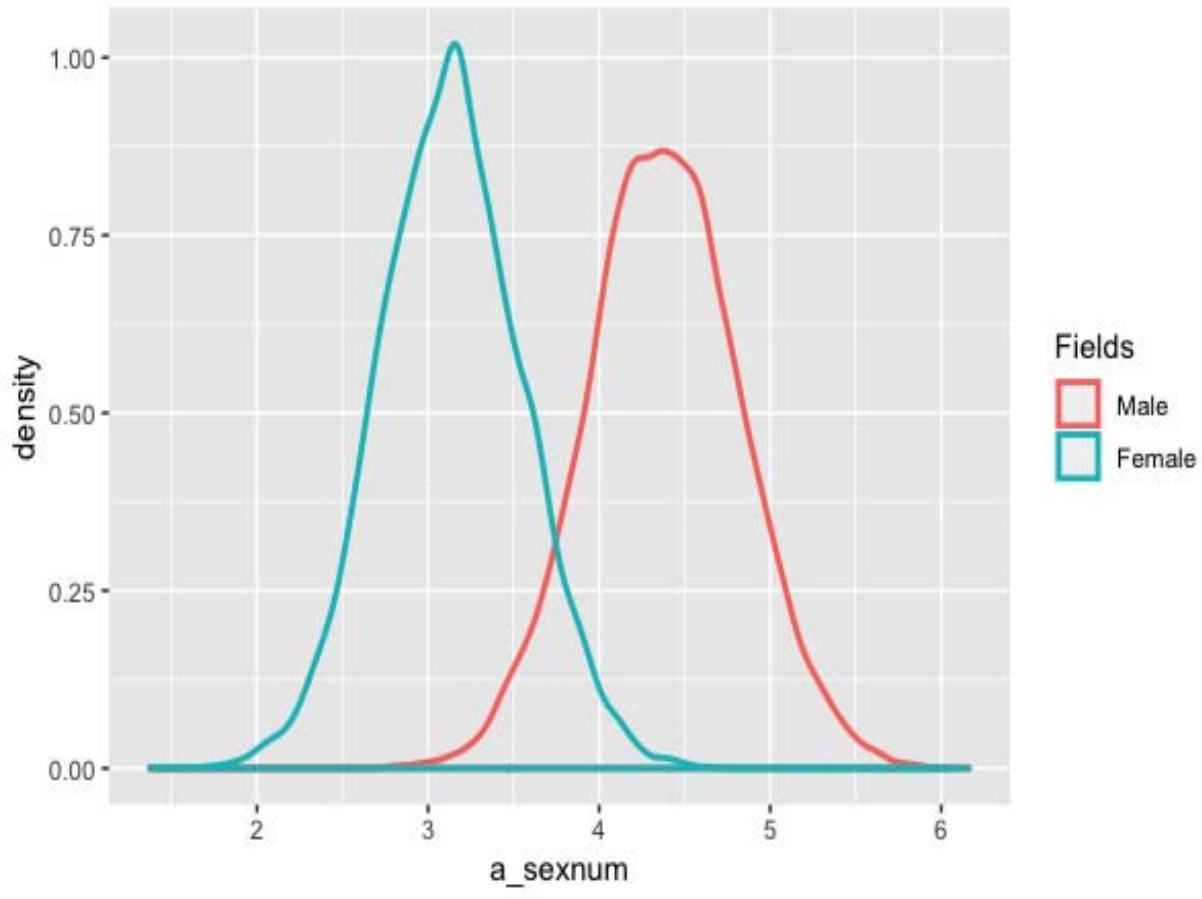

Fig 7c): Medicine 


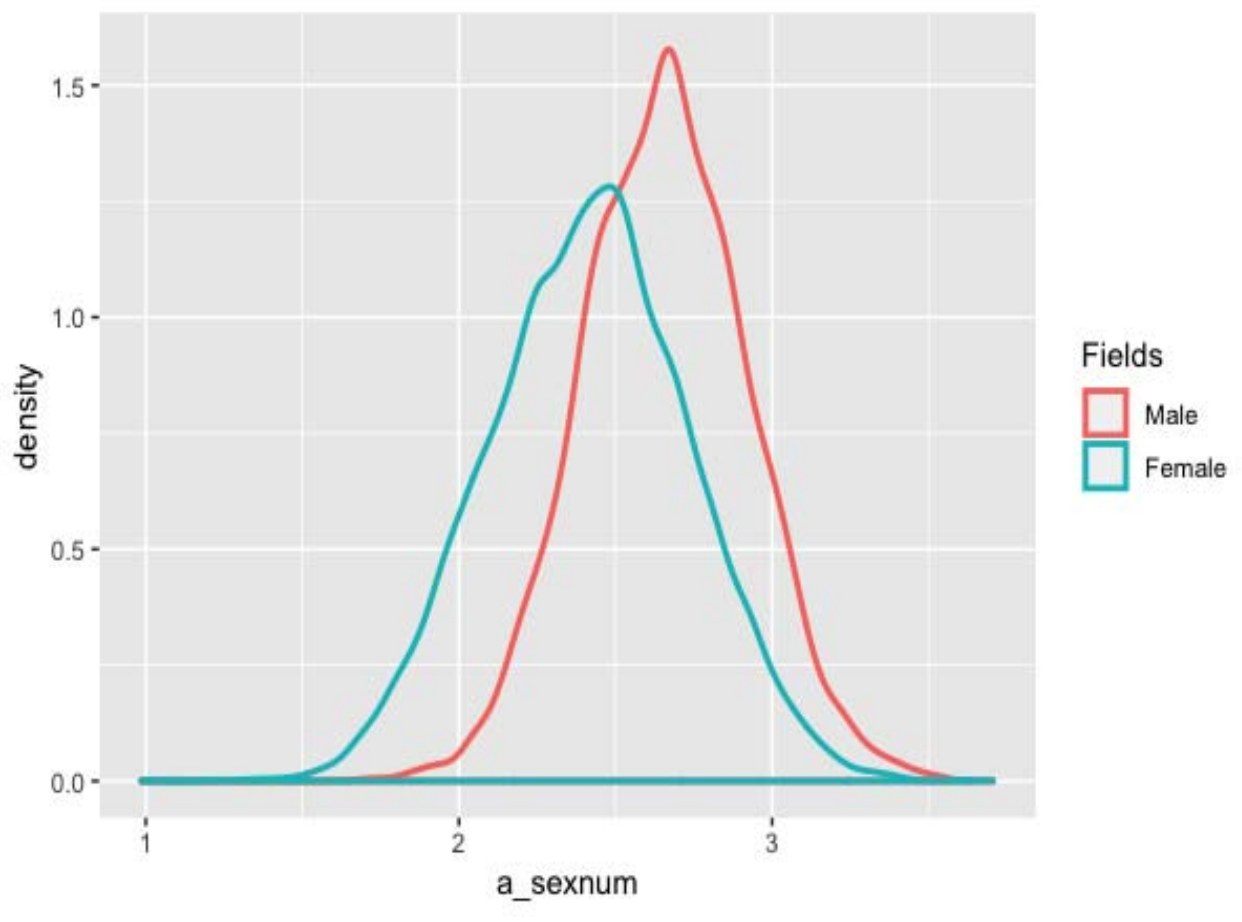

Fig 7d): Other fields

Figure 7: The Bayesian analysis of the article outcome according to gender and discipline

\section{New authors}

A new author is reported when the author appears in the SSHPA database for the first time during the period from 2008 to 2019. However, the data in 2008 was not accurate because all the authors inputted were considered as new authors, so the data from 2010 was supposed to provide higher accuracy. In general, the number of new authors among Social Sciences and Humanities fields had grown rapidly since 2017, which hinted at a significant increase in human resources that can carry out proper research (see Figure 8). During 2010 and 2018, the annual growth rate was approximately $21.82 \%$. 


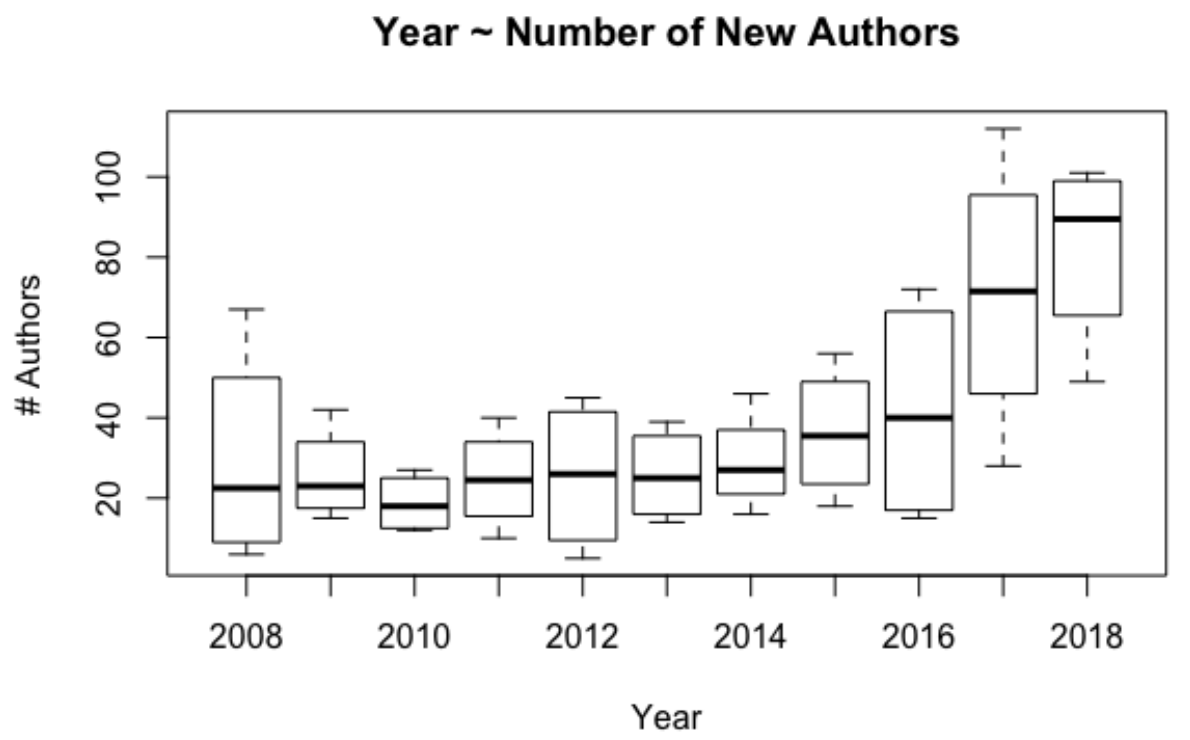

Figure 8: The number of new authors in Social Sciences and Humanities during 2008-2018

Figure 9 presents the variations in the number of new authors during the 2008-2018 period in four categories: Economics, Education, Social medicine, and Other fields. Notably, Economics discipline has reached the highest number of new authors within four categories in 2017 but gradually decreased afterward, in contrast with the rise of the other three disciplines. Economic and Other fields are the two areas with the highest number of new researchers in 2018, contributing to the total number of 497 and 460 researchers, respectively.

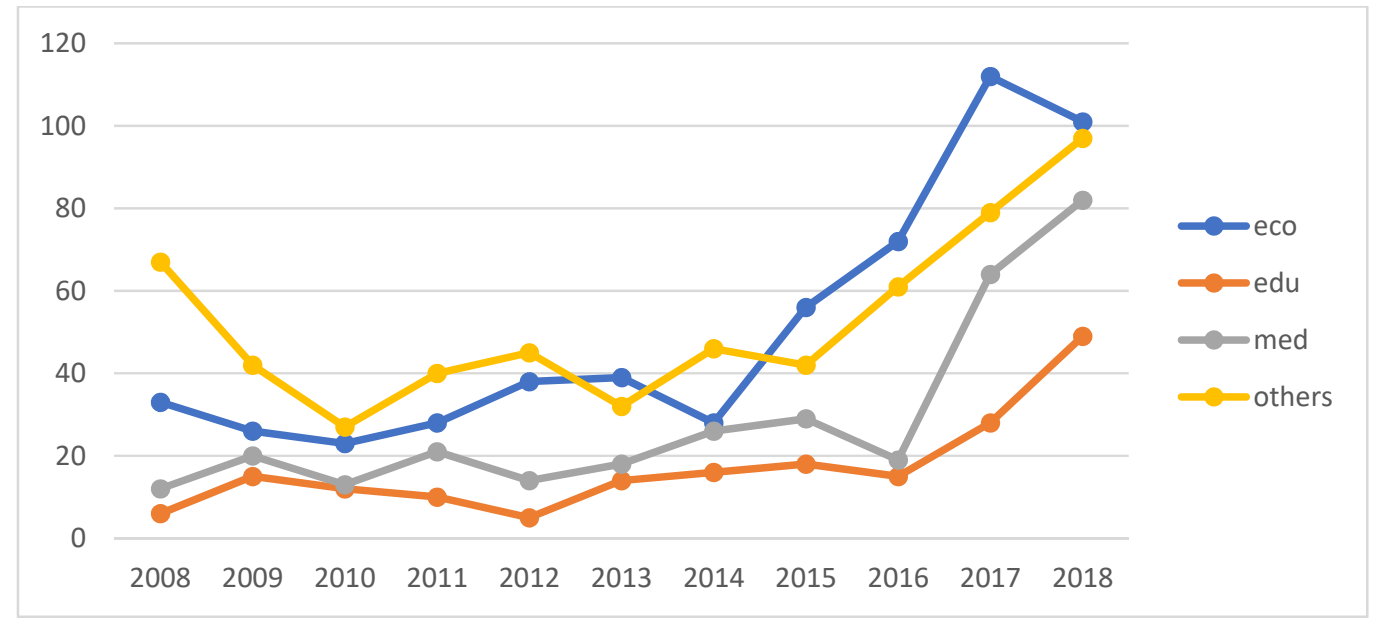

Figure 9: The number of new authors across disciplines during the 2008-2018 period

From Figure 10a to 10d, the number of new male and female researchers is on the rise in all fields, but they are in various numbers across fields. The number of new female researchers in Educational surge and even double the number of male counterparts in 2013 and 2018 (see Figure 10b). The distribution 
of new male and female authors in the Medical field is comparatively equal, and in some years - 2010, 2012, 2016, new female researchers exceed male researchers (see Figure 10c).

On the other hand, in the Economic and Other fields, the number of new male researchers has been dominant, despite the rapid growth of new female researchers.

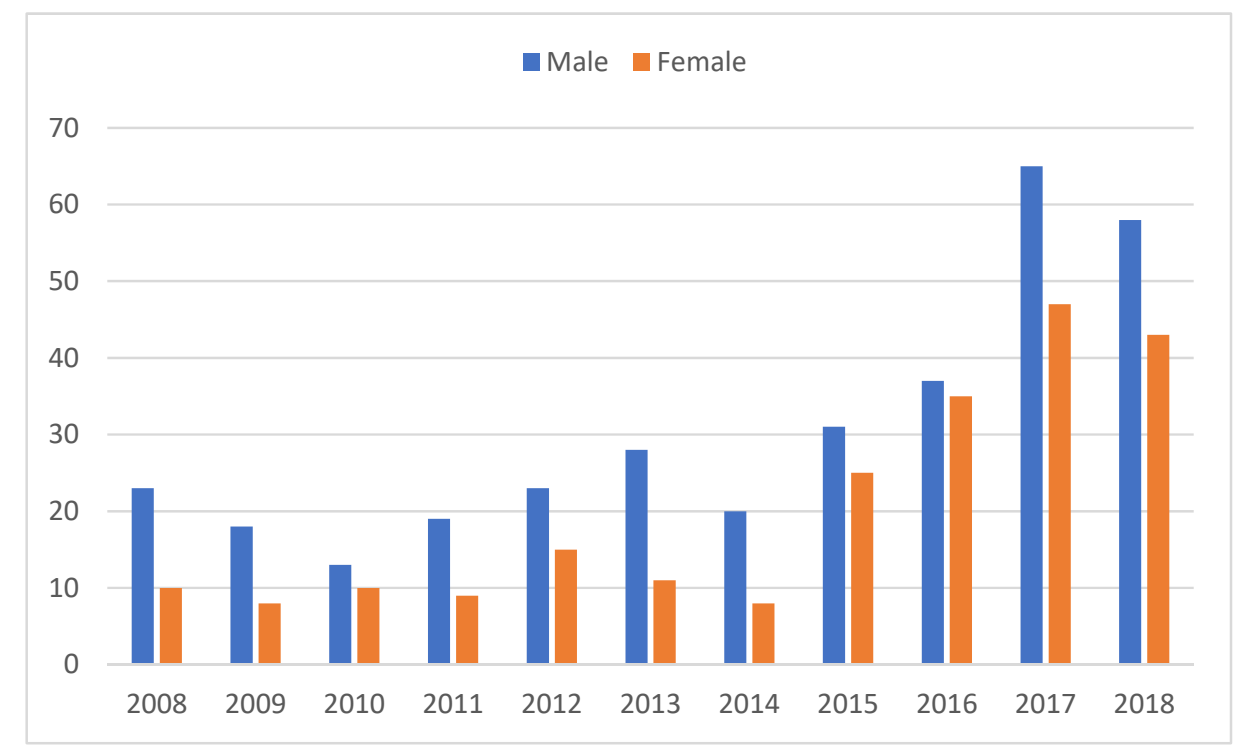

Fig 10a): Economic field

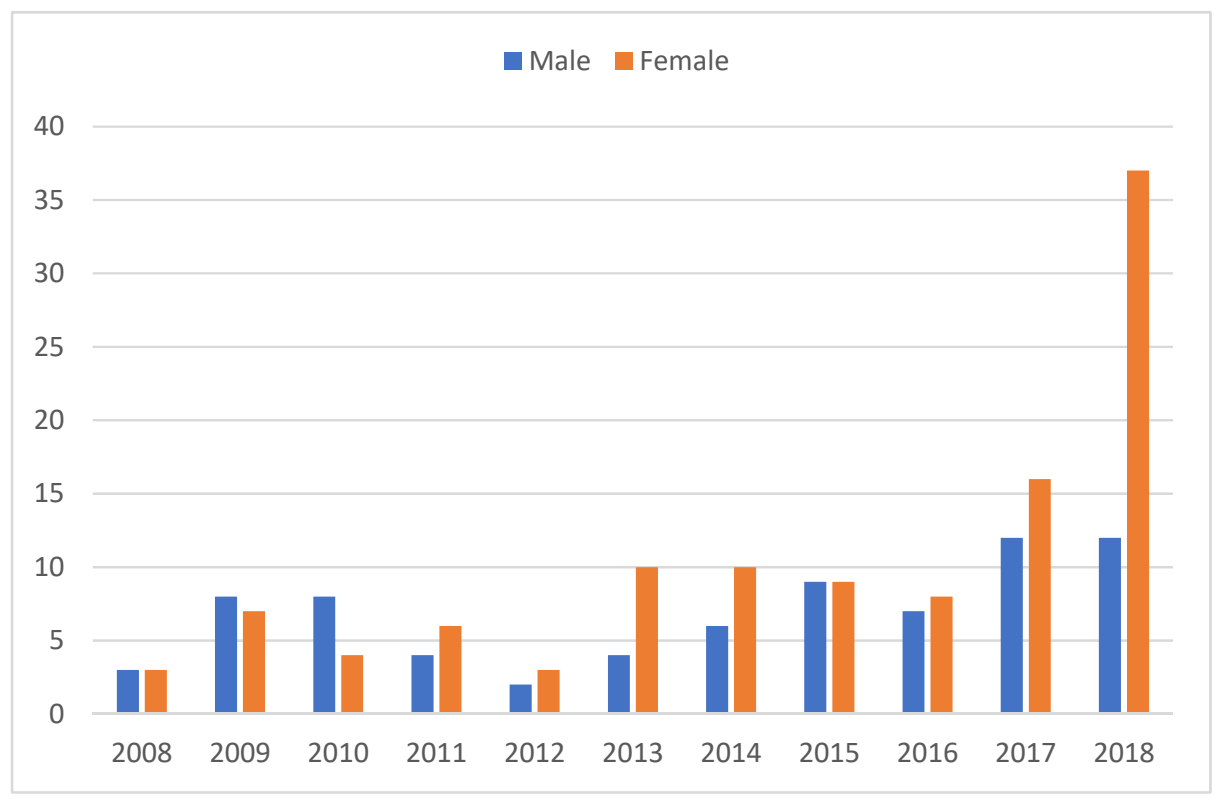

Fig 10b): Educational field 


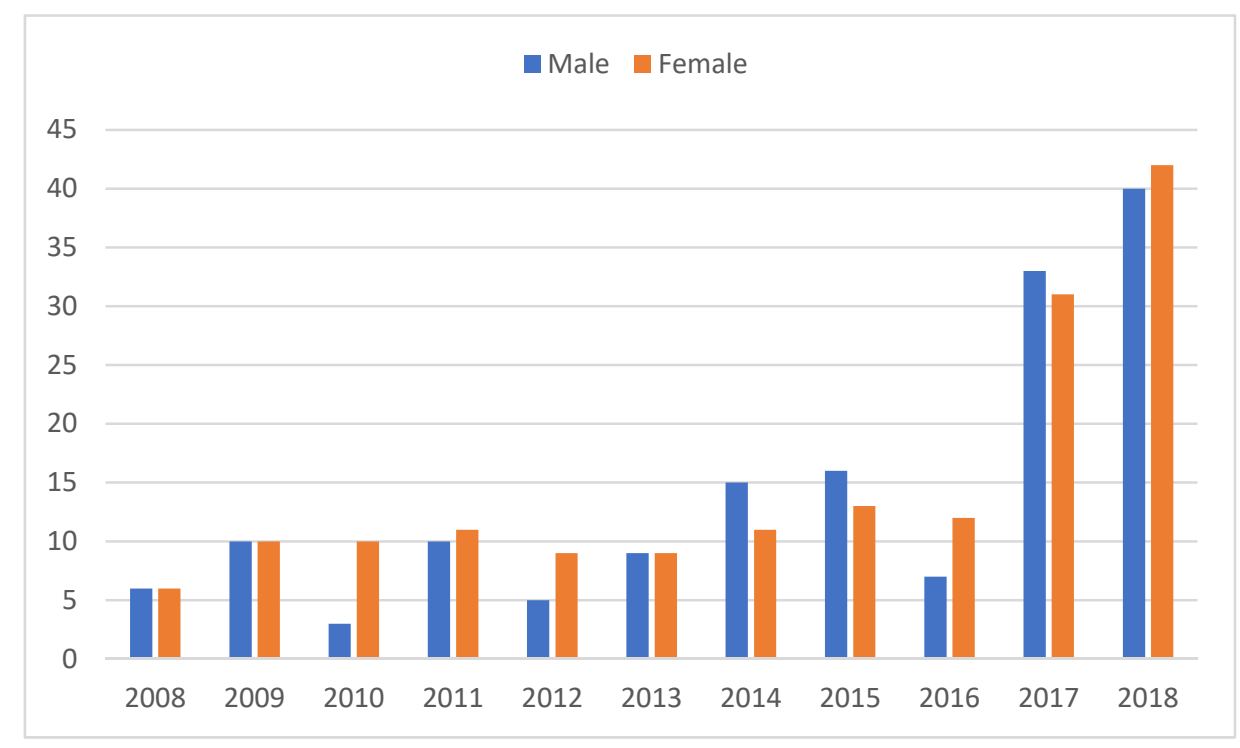

Fig 10c): Social medicine

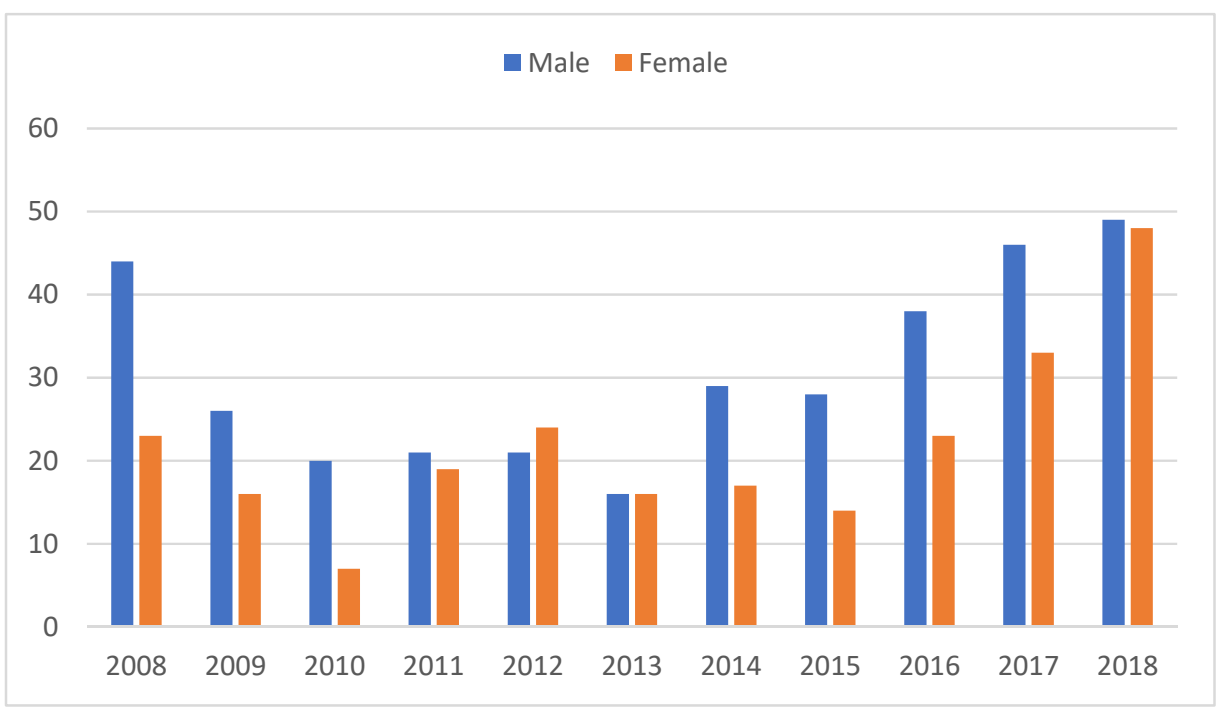

Fig 10d): Other fields

Figure 10: The number of new authors by gender and discipline during 2008-2018.

\section{Lead authors}

Lead authors are defined in this paper as authors who drastically outperform others in research output; they are comprised of outliers in the dataset. The numbers of new leaders are computed on a yearly basis. The figure below presents the growth in the number of new lead authors per year during the 2008-2018 period (see Figure 11). Each box plot represents the distribution of new lead authors by 
disciplines. There is a clear upward trend with small fluctuations; the overall increase is exponential, picking up steeply around the year 2014.

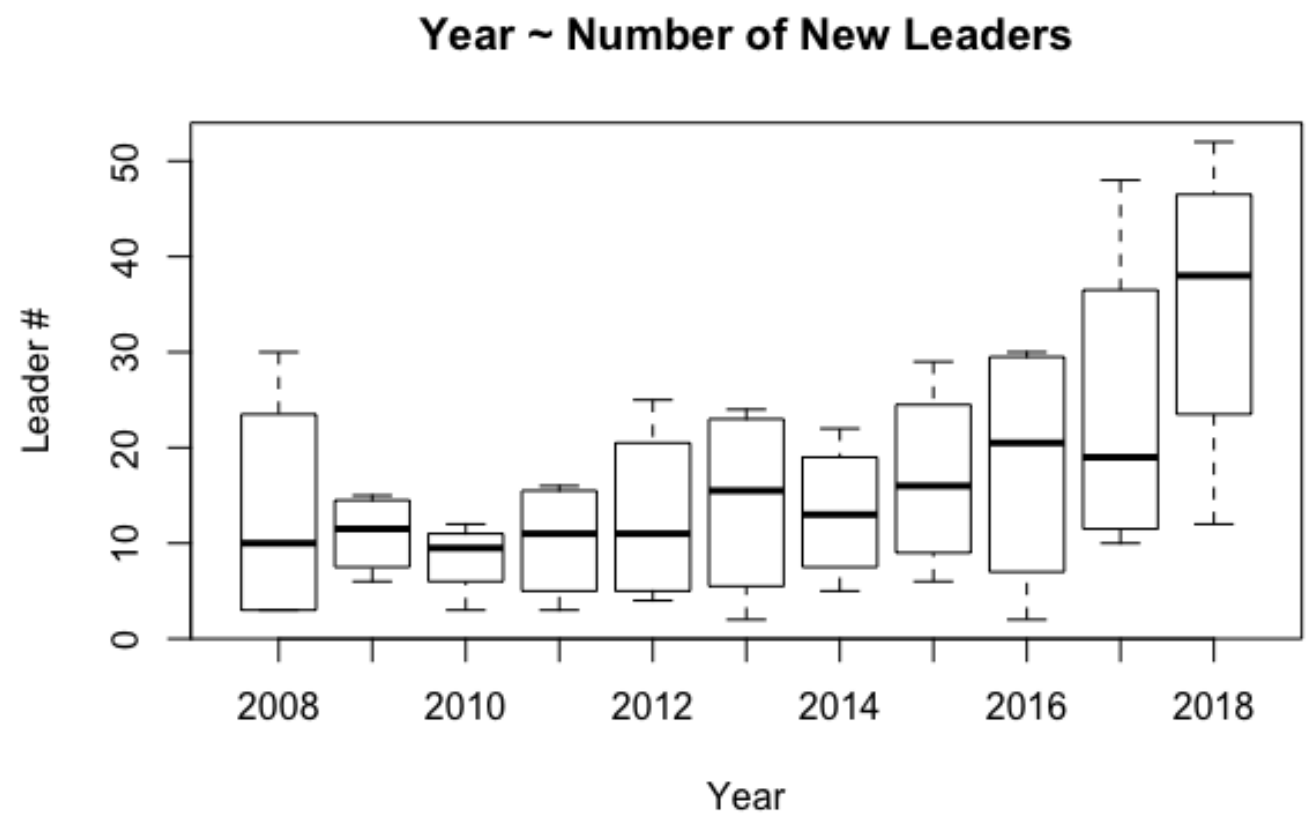

Figure 11. Number of new lead authors by year.

This section aims to answer the following questions: What is the profile of these outstandingly productive authors, and how do they differ from their average counterparts? We first study the mean age of lead authors, which is described in Figure 12. 


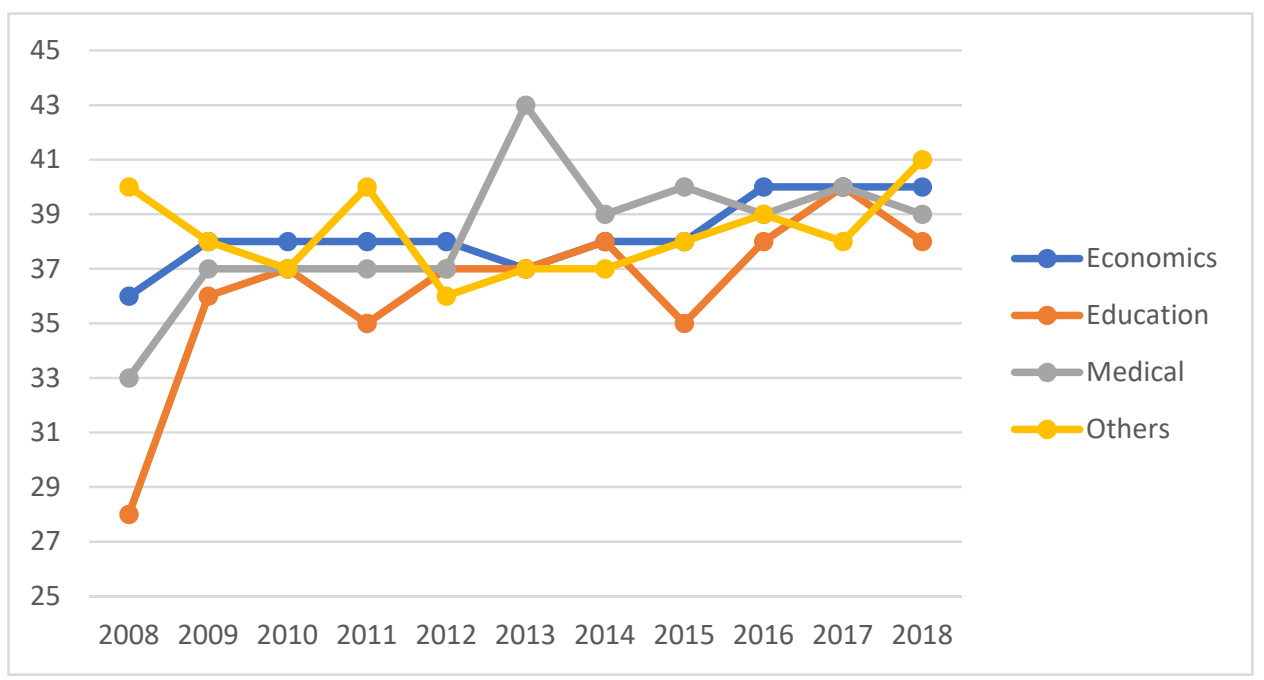

Figure 12. Mean age of leading authors by year and discipline.

The mean age of lead authors seems to hover around mid-thirties to early forties. There is a slight upward slope, suggesting that authors were having their "boom" in productivity at an increasingly older age. As a general observation, lead authors seem to be the youngest in Education and the oldest in Economics.

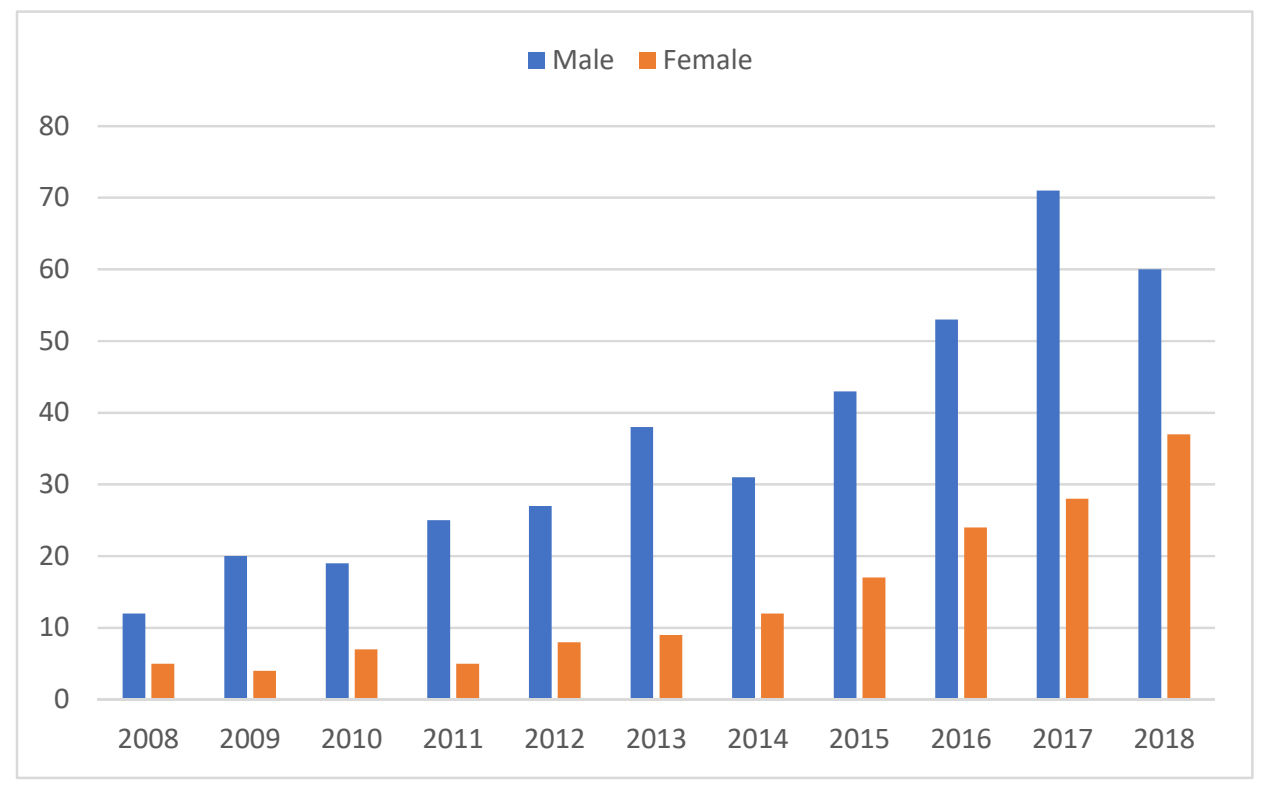

Fig 13a): Economic field 


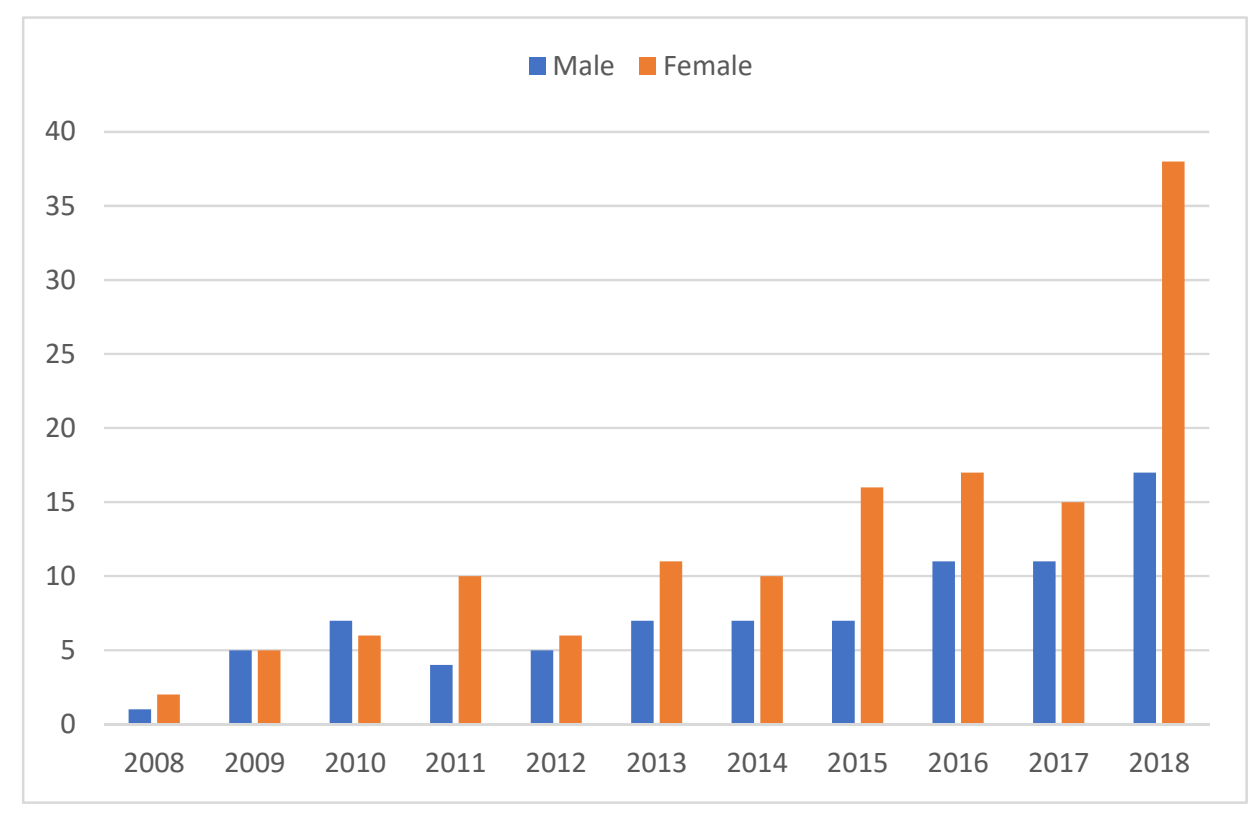

Fig 13b): Educational field

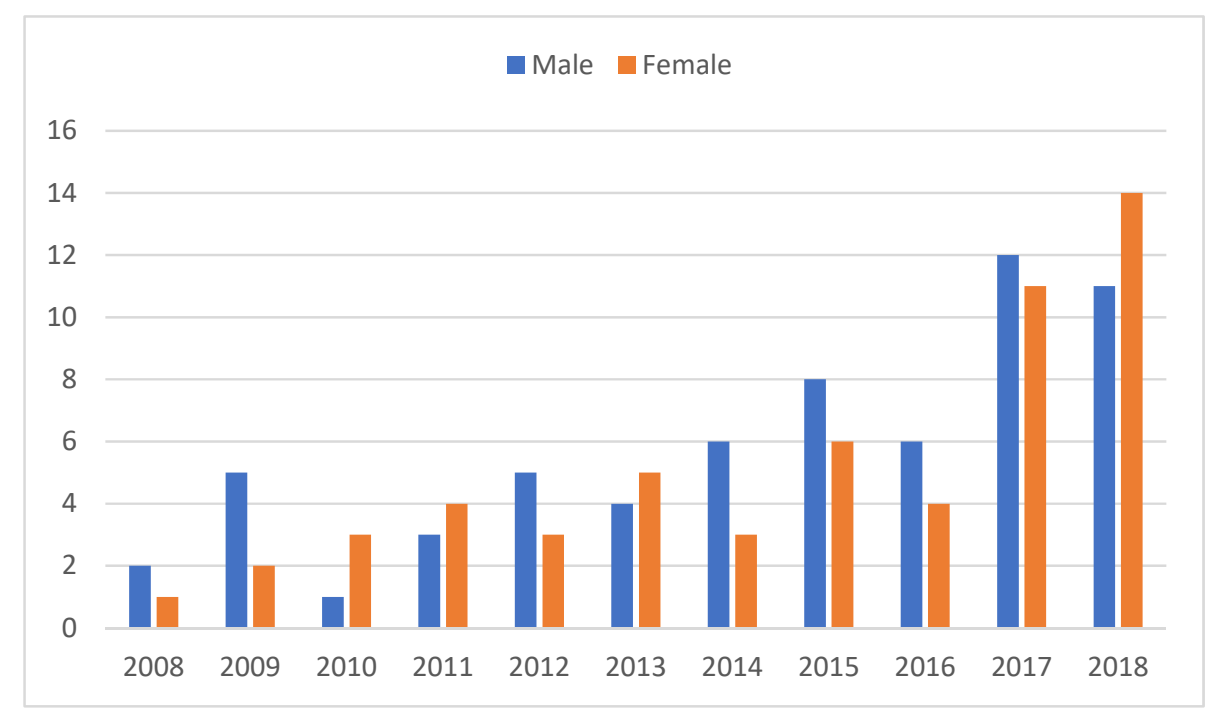

Fig 13c): Social medicine 


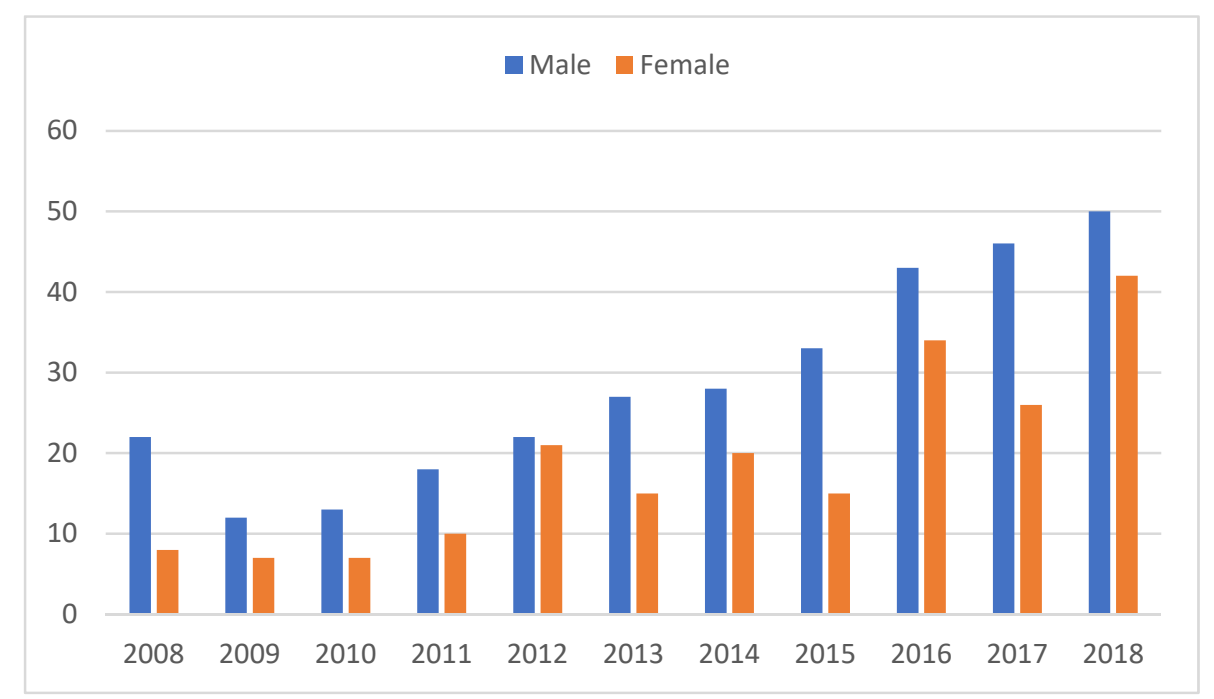

Fig 13d): Other fields

Figure 13. Number of the lead authors by gender and fields

Figure 13 provides a more detailed view of lead authors by gender in each discipline. As a general observation, there are more males than females, most noticeably in Economics where the number of males nearly doubles that of females. The reverse can be observed in Education, where women have consistently been dominating since 2011 and even have a drastic increase in 2018. The Medical discipline, on the other hand, seems to strike a delicate gender balance.

\section{Co-authorship}

The Social medicine field is the most collaboration-oriented field among disciplines; papers are usually published by groups of co-authors ranging mostly from 2 to 11 authors (see Figure 14c). In Economic and Other fields, most of the papers are written by 1 to 5 (co-)authors, but the dominance of solo paper is witnessed in Other fields (see Figure 14a and 14d, respectively). In contrast to the common collaborating trend, Education is relatively unique; papers in this field obtained a fewer number of coauthors than other disciplines (see Figure 14b). 


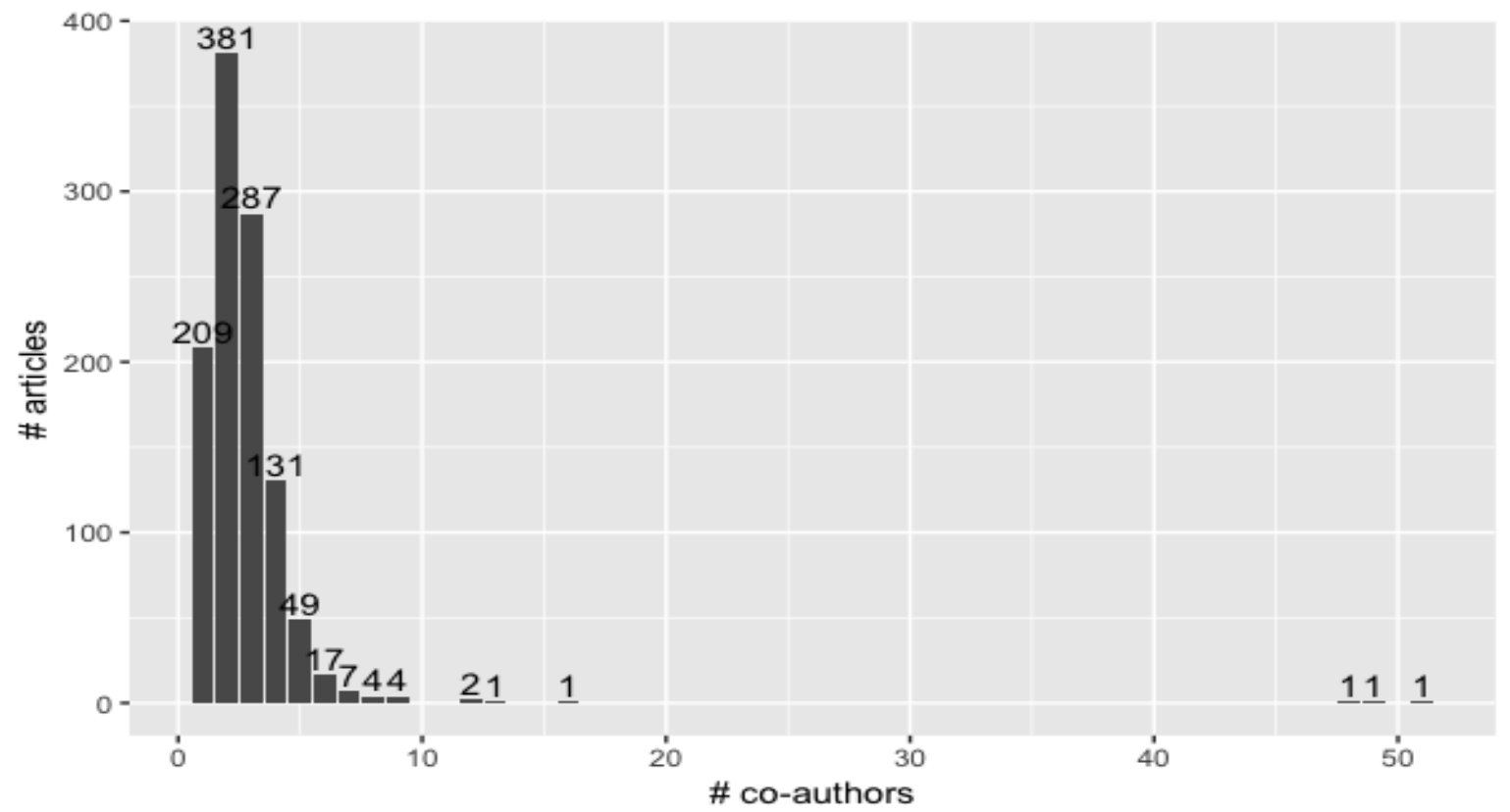

Fig 14a): Economics

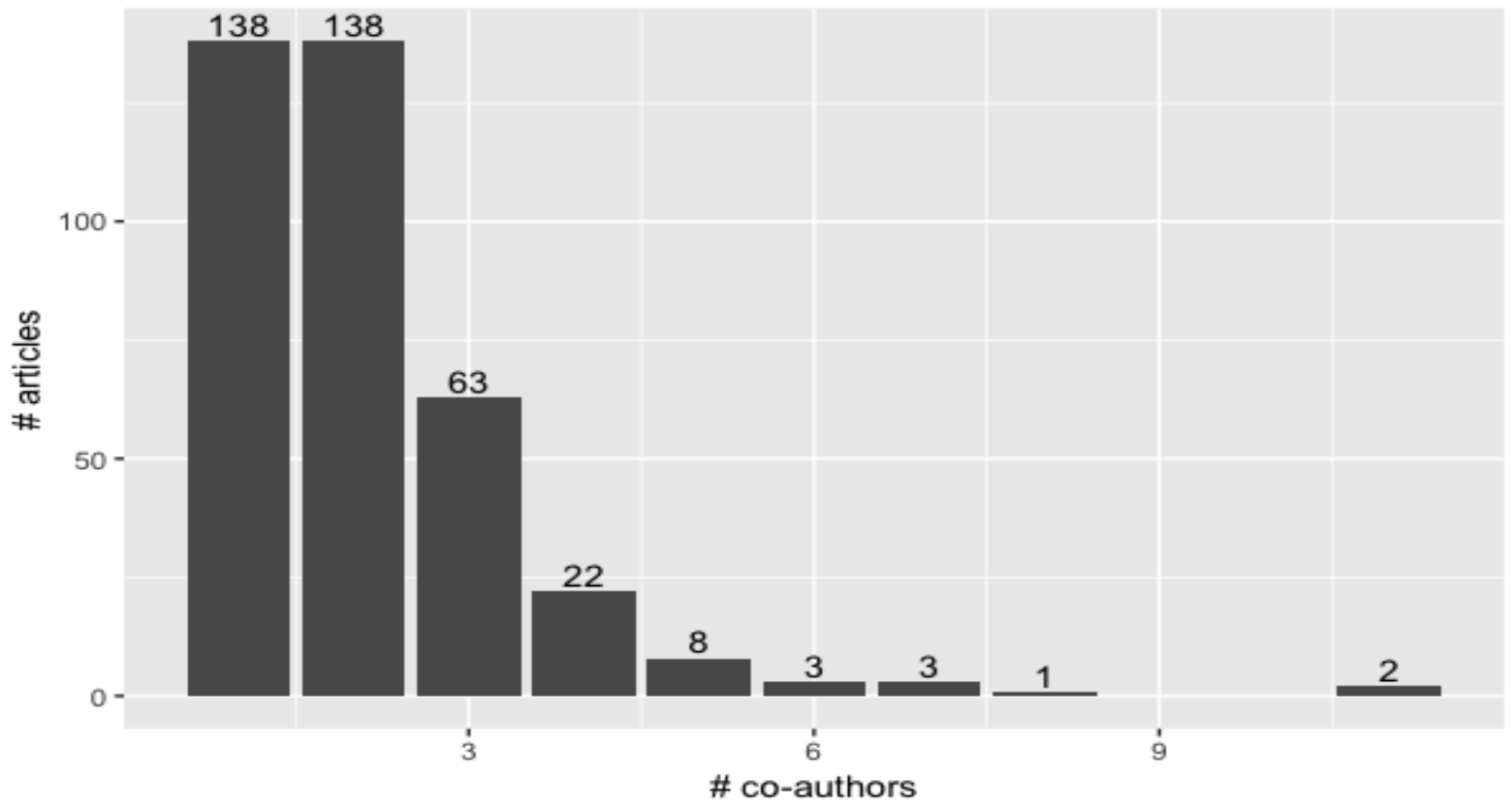

Fig 14b): Education 


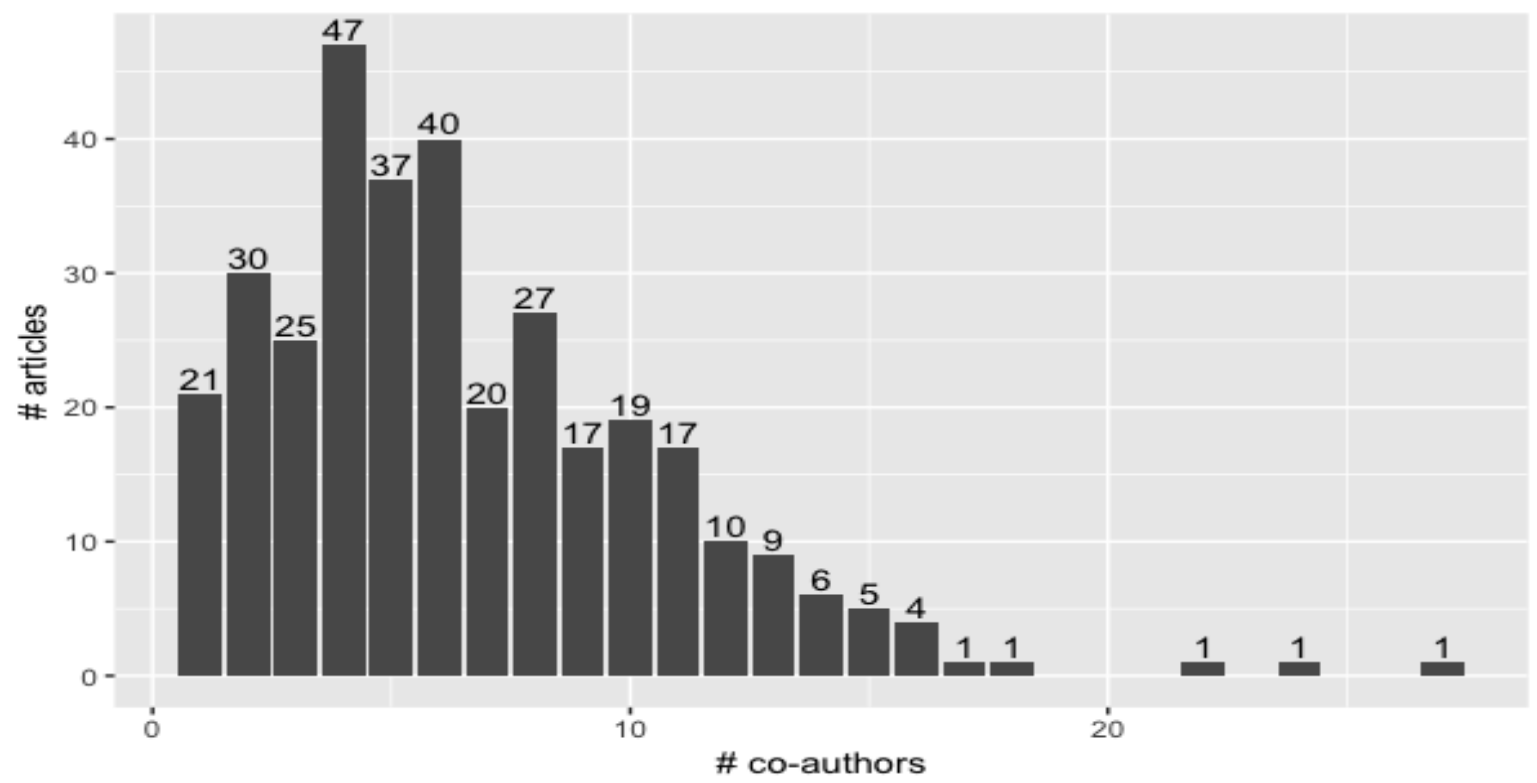

Fig 14c): Social medicine

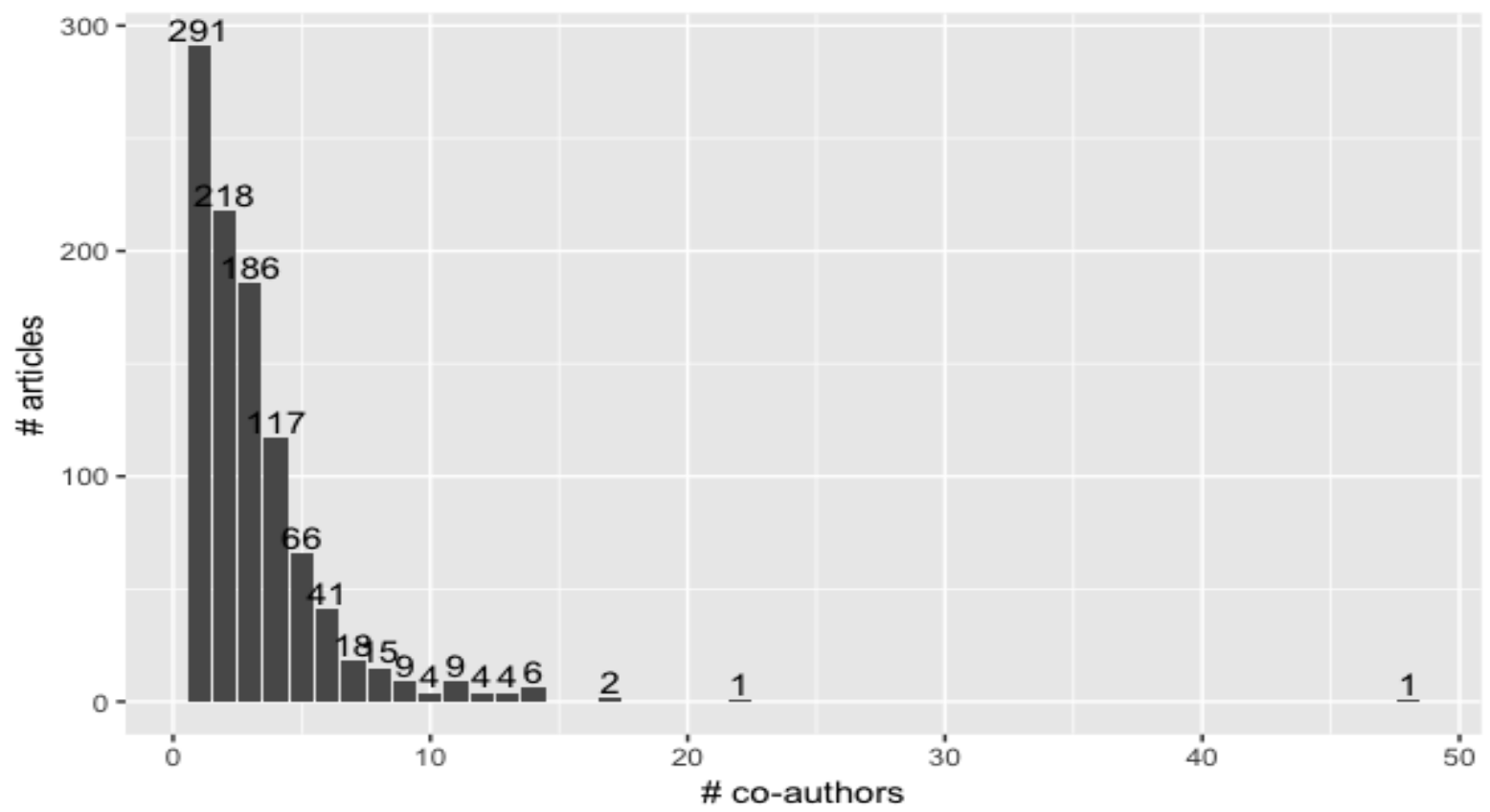

Fig 14d): Other fields

Figure 14. The distribution of articles according to the number of co-authors in each field 


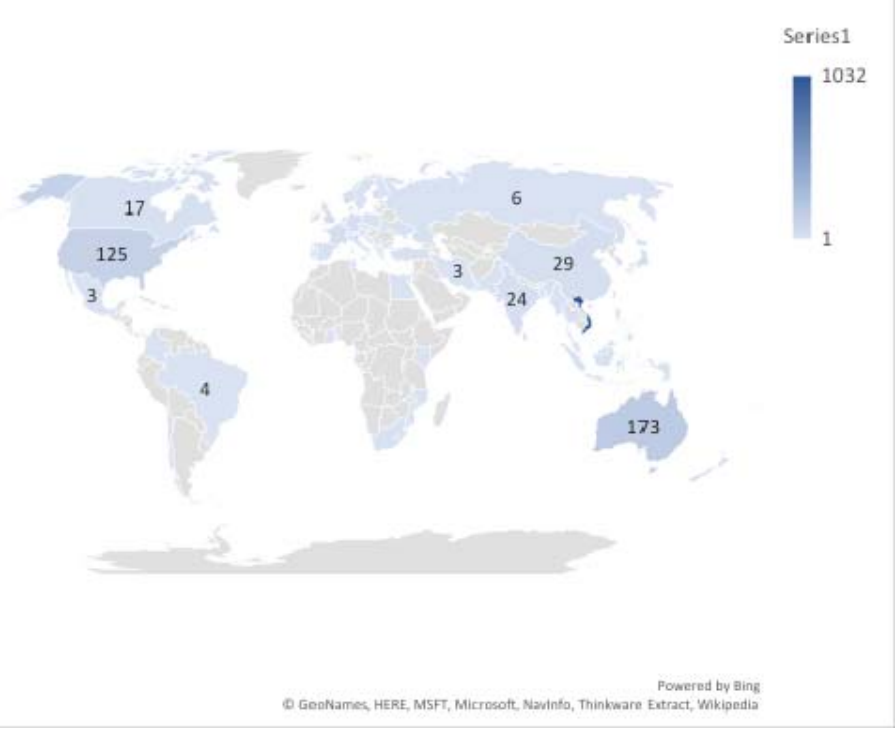

Fig 15a): Economics 


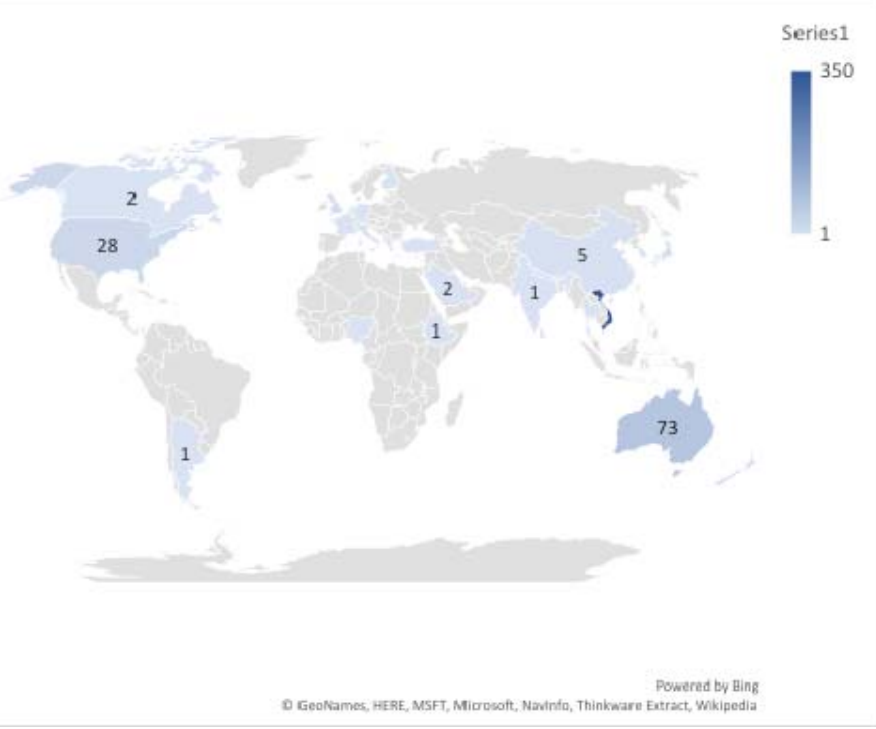

Fig 15b): Education

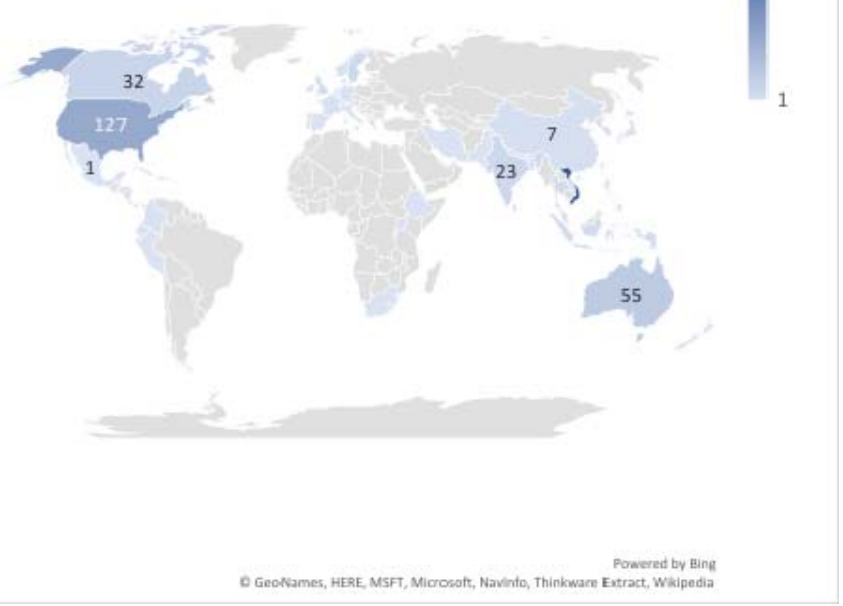


Fig 15c): Social medicine

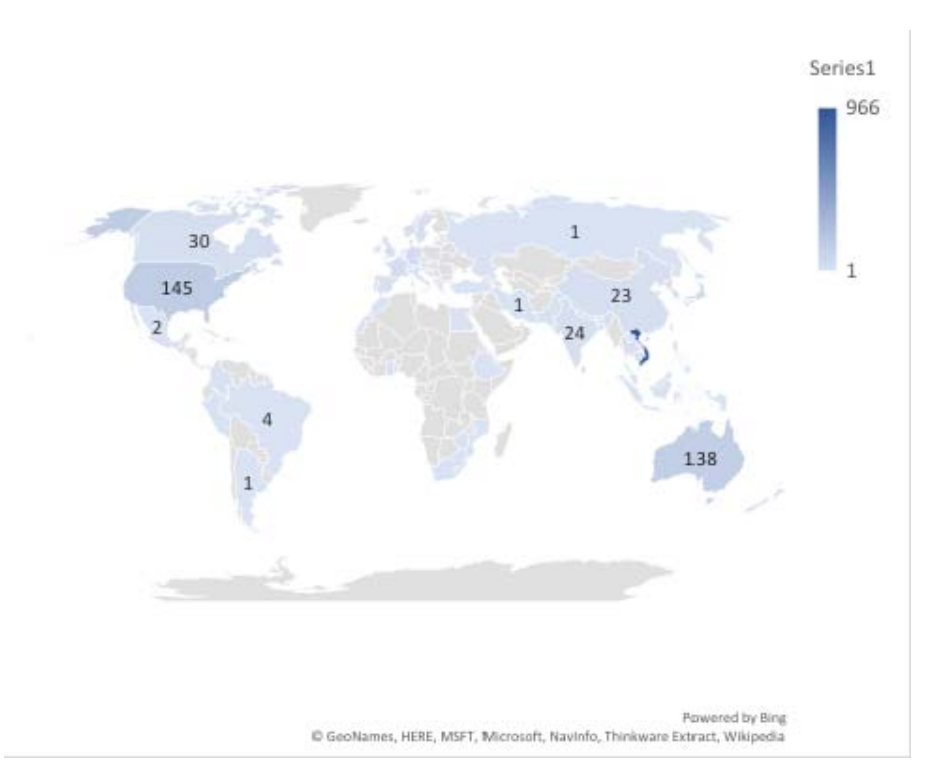

Fig 15d): Other fields

Figure 15: The distribution of international collaborations by countries among disciplines

Compared to Education and Social medicine, Economics and Other fields have a remarkably higher number of international partners with 62 and 56 countries (Figure 15), respectively; most of the collaborations are with a wide range of countries around the world. Meanwhile, the collaboration network in Education and Social medicine is narrow, with only 28 and 40 countries, respectively. Australia and North America are two major collaborating partners across disciplines, which indicates the collaborating tendency with Western developed countries within the Vietnamese scientific community.

\section{Journal Impact Factor (IF)}

Table 3 presents the percentage of articles according to the IF group among disciplines. Educational papers published in journals without IF occupies $75.7 \%$ of the total articles in the discipline, which is the highest proportion among the four areas. In contrast, articles in Medical fields obtain relatively high IF, as $65.4 \%$ of total articles have an IF higher than 1. The IF of papers in Economic and Other fields is comparatively even, and more than $90 \%$ of articles receive IF less than 3 (Table 4 ).

Table 4: The number and percentage of articles according to impact factor group among disciplines

\begin{tabular}{|l|l|l|l|l|l|l|l|l|l|l|l|}
\hline & $=0$ & $<=1$ & $<=2$ & $<=3$ & $<=4$ & $<=5$ & $<=6$ & $<=7$ & $<=8$ & $>8$ & Total \\
\hline
\end{tabular}




\begin{tabular}{|l|l|l|l|l|l|l|l|l|l|l|l|}
\hline Eco & $59.5 \%$ & $13.2 \%$ & $15.4 \%$ & $6.2 \%$ & $3.9 \%$ & $1.4 \%$ & $0.1 \%$ & $0.2 \%$ & $0.1 \%$ & $0.0 \%$ & 1011 \\
\hline Edu & $75.7 \%$ & $9.1 \%$ & $10.2 \%$ & $4.1 \%$ & $0.3 \%$ & $0.0 \%$ & $0.6 \%$ & $0.0 \%$ & $0.0 \%$ & $0.0 \%$ & 342 \\
\hline Med & $30.8 \%$ & $3.8 \%$ & $19.7 \%$ & $28.9 \%$ & $9.5 \%$ & $4.8 \%$ & $1.6 \%$ & $0.0 \%$ & $0.3 \%$ & $0.6 \%$ & 315 \\
\hline Other & $55.1 \%$ & $11.3 \%$ & $15.3 \%$ & $9.5 \%$ & $4.3 \%$ & $2.5 \%$ & $1.2 \%$ & $0.3 \%$ & $0.1 \%$ & $0.4 \%$ & 936 \\
\hline
\end{tabular}

Excluding articles published in journals without IF, papers led by Vietnamese researchers in the Economic and Educational fields were mainly published in journals whose IF was less than or equal to 2, while those in the Medical field were mostly published in journals whose IF ranged from between 2 and 3. The number of articles published in journals whose IF was more than 5 dropped dramatically, especially in the Educational field. Besides, there was merely one paper published in a journal with an IF of 8 or higher. In the Economic and Other disciplines, the average IF did not have a specific pattern and fluctuated erratically over time. During the 2010-2018 period, the Medical field observed a decreasing trend of average impact factor, whereas the Education field witnessed an increasing tendency of IF from 2014 to 2018. However, the Medical field still obtains the highest average IF at 2.58, while Other fields come after at 2.15 .

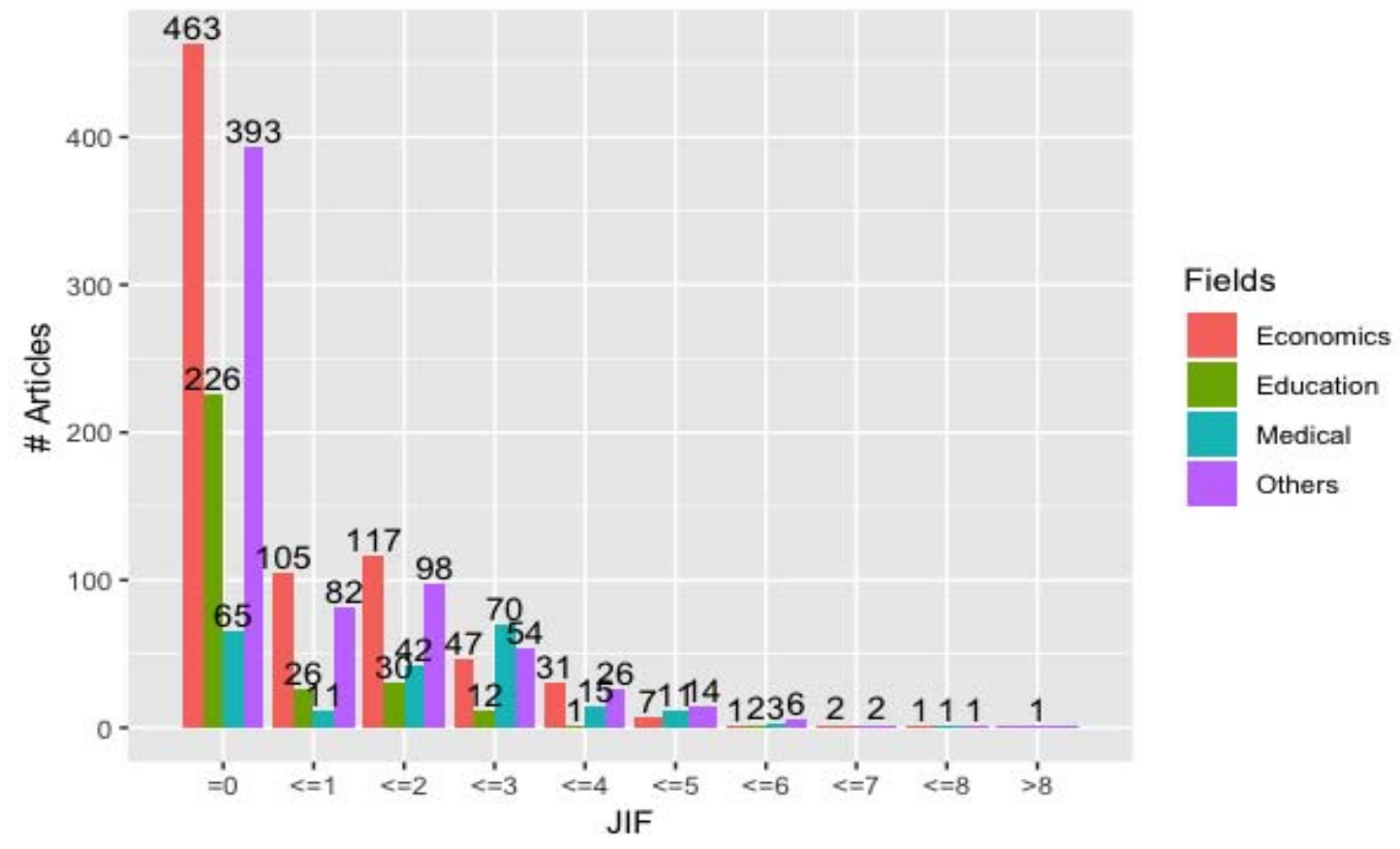

Figure 16: The number of articles led by Vietnamese researchers according to impact factor group among disciplines 
Overall, new male researchers were found to be older than female counterparts in almost fields Economic, Educational, and Other fields (Figure 16). In the Medical area, the average age of new male and female authors fluctuates over time and does not illustrate a clear pattern. The findings also suggest lead authors of Vietnamese SSH are often around mid-thirties to early forties, with the oldest in Economics and youngest in Education. It is remarkable that new female Economic authors are much younger than males, but the age gap has gradually diminished since 2014. All the figures suggested an improvement in terms of gender balance in Vietnamese SSH; however, one must not overlook the fact that the majority of researchers remained in Economics, the discipline with stark male dominance. Economics was also the discipline receiving the most investments, grants and regarded as the most substantial social science discipline, especially for their role in national growth. More on this will be discussed in detail in the following section.

\section{Discussion}

\section{The limitation of the study}

This study has several limitations. Firstly, the cause and effect relationship between the research policies and scientific productivity cannot be fully established in this research. However, as this paper looks at research output in three periods, each marked by a specific policy change, the findings can still be useful for our understanding of the matter. Future studies can employ more sophisticated methods to explore questions that relate to each field in SSH research and how to increase the publication of each discipline while balancing their scientific productivity. Secondly, the analysis exclusively focuses on the SSH scientific productivity in Vietnam with its domestic changes in research policies; therefore, the findings should be interpreted within this context. Nonetheless, as this paper has provided a basic understanding of the development of a nascent SSH research community in Vietnam in the last 12 years, the findings would still be useful for policymakers from other developing countries who look for boosting their scientific productivity through policy changes.

\section{The inequality in age groups and disciplines}

In the foreseeable future, the 40-44 age group will continue to play a crucial role in the development of Vietnam SSH, especially the Economics discipline. $48 \%$ of the Economics articles are coming from this age group during the 2008-2018 period. Previous economic models assumed the declining productivity among older workers (Greller and Simpson, 1999); however, it is clear that things work out differently in academia. A Ph.D. candidate is expected to finish his/her Ph.D. and enter the job market in the early 30s, then supposed to prove his/her skills through publications to have an advantage towards a position in a highly competitive job market (Donnelly et al., 2019). Therefore, the $40-44$ age group might be the best period to produce quality scientific research with roughly ten years of experience and knowledge. It appears that the data agree with this expectation of the reality of academia.

This study also shows the leading position of Vietnamese Economics discipline after the new policies in 2014 and 2017. Firstly, the productivity of Economics author ranks first in two main age groups, which are 35-39 (305 articles) and 40-44 (334 articles). Also, in terms of the number of authors and new authors, Economics is dominant comparing to the other three disciplines. From 2014 to 2018, the number of new authors in Economics has risen from 30 to roughly 100 people. Finally, the Economics 
discipline also surpassed the others in terms of international collaborations, with 860 articles resulted from international collaborations and up to 62 collaborating countries. Indeed, the result is in accordance with the previous study, which emphasized the leading role of Economics in the rapid development of Vietnamese SSH in recent years (Vu et al., 2019).

The analysis in this study also revealed that the position of Economics is shaken by the substantial growth rate of new researchers in the Medical and Educational fields starting from 2014 to 2018. In the near future, the development of SSH in Vietnam is expected to be fueled by scientific production from not only Economics but also Education and Social medicine. Nevertheless, policymakers could learn from the success of the Economics discipline and consider applying suitable policies to the other fields for better use of resources (Q.-H. Vuong, 2018b).

\section{Gender disparity}

In this paper, we have not identified any author that belongs to the LGBTIQ+ group and applied the SAGER guideline to define the research groups, which are male and female (Heidari et al., 2016). Previously, a large body of international scholarly literature has developed to address gender disparity in science and science education (Tindall and Hamil, 2004). Women are believed to be under-represented in science (Clark Blickenstaff, 2005). Our study found that the number of publications and the number of researchers in Economics and Other fields during the 2008-2018 period were dominated by males.

In 2014, there was a decrease in the number of new male authors in Economics after the announcement of ISI/Scopus as standard for the research project, in contrast with the increase in the other three disciplines. However, this number recovered and reached its peak in 2017, which suggests the positive signal of adaptive ability in Economics fields. The finding hints at the low reinforcement rate of new young female researchers, thus raising the concern about the inequalities that hinder women's access to science in Vietnam. The average age of male researchers is also higher than female researchers in all fields. According to Tran (2019), the biggest challenge for more include more female researchers is that policy implementation has not taken into account specific characteristics, such as social prejudice or early retirement age for women.

On the positive side, Education is the field where female has been outperforming their male counterparts. Interestingly, results from the study point out that female researchers in Education surpassed their male peers in terms of number and output, and the productivity level rocketed after policies' changes in 2017. This finding can be explained with an understanding of the cultural context in Vietnam, in which Education-related jobs are believed to be ideal for women (Larivière et al., 2013). We also found that the number of new female authors almost equalized with their counterparts in the Social medicine field and even overshadowed the number of new male authors in the Educational field. The finding signals a small percentage of gender disparity in Medical and Educational fields. Nonetheless, given the ongoing imbalance between the reinforcements of male and female new authors in Economics and Other fields, policymakers are suggested to target Economics and Other fields for confining gender inequalities and pay attention to the negative aspects that can hamper the access and progress of women in science (Larivière et al., 2013). 
Chairwoman of Vietnam Women's Union at the eighth meeting of the International Network of Women Engineers and Scientists 2018 Asia and Pacific Nations Network (INWES-APNN), Nguyen Thi-Thu-Ha, declared that scientists and women, in particular, were playing an important role in the sustainable development of each country and the global (VNS, 2018a). Recorded data proved that the number of female scientists and intellectuals has gradually increased. The proportion of masters' degree earners who are women in 2014 was 43 percent, of Ph.D. earners was 21 percent, and of professors and associate professors was 24.6 percent for the 2012-16 period, she stated. Promoting female researchers is also an effective way of breaking the barriers, creating competitiveness, and pushing the boundary of science in the nation (Vuong, 2019a). Therefore, it is possible that more and more female scientists are willing to participate in the SSH publication race in no time, and the country should not miss the opportunity to invest in them.

\section{International standard adaptation}

Among the four different disciplines, Education appears to have less international collaboration. Unlike Education, authors in the other three fields prefer international and broader group collaboration, especially Economics. The increase in cases of scientific co-authorships and international collaborations among disciplines of Social Sciences in Vietnam during the 2008-2018 period might result from the Vietnamese government's pursuit of science policies incentivizing research groups and international collaboration (Nhan, 2017; Nguyen et al., 2019). Besides incentives given by the government, the pressure from 'publish or perish' can be another explanation for the rising co-authoring and international collaborating patterns. As Ph.D. students in Vietnam have been required to obtain at least two publications in international journals for qualification since 2017, the co-authoring tendency between supervisors and students has become more popular (Price et al., 2000; Fisher et al., 2013; Vuong, 2019a). This appears to be aligned with a common global trend, in which the average number of co-authors, the share of co-authored, and international co-authored articles in Social Sciences are increasing (Henriksen, 2016). With the expansion of the Internet and the increasing pressure to publish as quickly as possible (Yucha, 2015), Vietnamese authors in each discipline should be prepared for more international cooperation.

Results also show that the ability of Vietnamese SSH researchers to publish in high IF journals depends on the nature of each field. In Economics, more than $50 \%$ of the field's output was in publication with no IF, while publications with IF from 1 to 2 occupied $28.6 \%$ of the field's output. Also, the articles published in the Educational field were observed to be in relatively low IF journals. In contrast, Medical field related papers had the highest IF; accounted for more than $65 \%$ of the total publications. Vietnam is showing signs of a growth phase of building up the country's Social Medicine research capacity. In summary, there is necessary for a nation to balance its quantity and quality of scientific output to advance further; Vietnam SSH will require more quality publications in each discipline to establish a more mature scientific community.

\section{Conclusion}

By glimpsing the working life of more than 1,500 Vietnamese researchers in $\mathrm{SSH}$, this study has sought to bring useful empirical evidence on the status of different disciplines after the introduction of new research policies. First, in terms of the absolute number of publications, authors of the 40-44 age group 
have the most contribution across all disciplines. As Vietnam's SSH strives for the full assimilation of international publication standards, decision-makers must incorporate the viewpoints and -practical lessons of the 40-44 age group in policy formation so as to continuing pushing the quantity and quality of the publication. Second, contrary to the strong international collaboration-oriented tendency in Social medicine, Economics, and Other fields, Education authors have fewer cases of international collaboration. Therefore, it is recommended to increase the knowledge exchange opportunities for Vietnamese researchers in Education, such as creating international meetings or workshops where people can connect and expand their network in the global SSH researcher community. This goes along with the global trend to promote open science, open dialogue, and open data (Vuong, 2020; Vuong, 2017). Finally, the underrepresentation of female researchers in all fields, shown in this study, should be concerning. However, given there are different levels of severity of this problem for different fields, policy to minimize this problem should be sensitive to the sociological and cultural context of each field. Understanding the changes after the introduction of past policies will enable thoughtful reflection for the formation of future policies.

\section{Figure legends}

Figure 1: Timeline of main SSH research policies in Vietnam 2008-2018.

Figure 2. The average age of researchers in each field by year.

Figure 3. The average number of papers in each age group.

Figure 4. The Bayesian analysis of the productivity of researchers according to age and discipline.

Figure 5: The total number of publications by gender and discipline.

Figure 6: The number of researchers by gender and discipline.

Figure 7: The Bayesian analysis of the article outcome according to gender and discipline

Figure 8: The number of new authors in Social Sciences and Humanities during 2008-2018.

Figure 9: The number of new authors across disciplines during the 2008-2018 period.

Figure 10: The number of new authors by gender and discipline during 2008-2018.

Figure 11. Number of new lead authors by year.

Figure 12. Mean age of leading authors by year and discipline.

Figure 13: Number of lead authors by gender and fields.

Figure 14: The distribution of articles according to the number of co-authors in each field.

Figure 15: The distribution of international collaborations by countries among disciplines.

Figure 16: The number of articles led by Vietnamese researchers according to impact factor group among disciplines

\section{Competing interests}

The author(s) declare no competing interests. 


\section{Data availability}

The data is available in OSF. Identifier: DOI 10.17605/OSF.IO/CP35H; URL: https://osf.io/cp35h/

\section{Acknowledgments}

This research is funded by the Vietnam National Foundation for Science and Technology Development (NAFOSTED) under the National Research Grant No. 502.01-2018.19.

\section{References}

Abritis A, McCook A and RetractionWatch (2017) Cash bonuses for peer-reviewed papers go global. Science.

Adams J, Pendlebury D, Rogers G and Szomszor M (2019) Global Research Report - South and East Asia: Institute for Scientific InformationWS385512528 / 01). Available at: https://clarivate.com/webofsciencegroup/campaigns/south-and-east-asia/.

Clark Blickenstaff J (2005) Women and science careers: leaky pipeline or gender filter? Gender and Education 17(4): 369-386.

Donnelly K, McKenzie C R M and Müller-Trede J (2019) Do Publications in Low-Impact Journals Help or Hurt a CV? Journal of Experimental Psychology: Applied \$V OnlineFirst: 1.

Fisher B S, Cobane C T, Vander Ven T M and Cullen F T (2013) How Many Authors Does It Take to Publish an Article? Trends and Patterns in Political Science. PS: Political Science \& Politics 31(4): 847-856.

Glänzel W (1996) A bibliometric approach to social sciences. National research performances in 6 selected social science areas, 1990-1992. Scientometrics 35(3): 291-307.

Harman G (2010) The research role of Vietnam's universities. Reforming higher education in Vietnam. Springer, pp. 87-102.

Heidari S, Babor T F, De Castro P, Tort S and Curno M (2016) Sex and Gender Equity in Research: rationale for the SAGER guidelines and recommended use. Research Integrity and Peer Review $1(1): 2$.

Henriksen D (2016) The rise in co-authorship in the social sciences (1980-2013). Scientometrics 107(2): 455-476.

Hicks D (1999) The difficulty of achieving full coverage of international social science literature and the bibliometric consequences. Scientometrics 44(2): 193-215.

Hicks D (2004) The four literatures of social science. In: Moed, H.F., Glänzel, W. \& Schmoch, U. (eds) Handbook of Quantitative Science and Technology Research. Springer: Dordrecht, Netherlands, pp. 473-496.

Hien P D (2010) A comparative study of research capabilities of East Asian countries and implications for Vietnam. Higher Education 60(6): 615-625. 
Ho T M, Nguyen H V, Vuong T T, Dam Q M, Pham H H and Vuong Q H (2017) Exploring Vietnamese coauthorship patterns in social sciences with basic network measures of 2008-2017 Scopus data. F1000Research 6: 1559.

Author (2019) bayesvl: Visually Learning the Graphical Structure of Bayesian Networks and Performing MCMC with 'Stan'. Available at: https://cran.r-project.org/web/packages/bayesvl/index.html.

Larivière V, Ni C, Gingras Y, Cronin B and Sugimoto C R (2013) Bibliometrics: Global gender disparities in science. Nature 504(7479): 211-213.

Line M B (2000) Social Science Information - The Poor Relation. IFLA Journal 26(3): 177-179.

Lowe R A and Gonzalez-Brambila C (2007) Faculty entrepreneurs and research productivity. The Journal of Technology Transfer 32(3): 173-194.

Manh H D (2015) Scientific publications in Vietnam as seen from Scopus during 1996-2013. Scientometrics 105(1): 83-95.

Nafosted (2018) Quỹ Phát triển Khoa học và Công nghệ Quốc gia: 10 Năm Hình thành và Phát triển 2008 - 2018 [National Foundation for Science and Technology Development: 10 Years of Foundation and Development 2008 - 2010]. Hanoi, Vietnam: NXB Khoa học và Kỹ thuật.

Nguyen H-K T, Nguyen T-H T, Ho M-T, Ho M-T and Vuong Q-H (2019) Scientific publishing: the point of no return. In: Vuong, Q.-H. \& Tran, T. (eds) The Vietnamese Social Sciences at a Fork in the Road. De Gruyter: Warsaw, Poland, pp. 143-162.

Nguyen T V, Ho-Le T P and Le U V (2017) International collaboration in scientific research in Vietnam: an analysis of patterns and impact. Scientometrics 110(2): 1035-1051.

Nguyen T V and Pham L T (2011) Scientific output and its relationship to knowledge economy: an analysis of ASEAN countries. Scientometrics 89(1): 107-117.

Nhan T (2017) 'NAFOSTED đầu tư cho nhóm nghiên cứu mạnh [NAFOSTED funds strong research teams]', Tia Sáng. Available at: http://tiasang.com.vn/-khoa-hoc-cong-nghe/NAFOSTED-dau-tucho-nhom-nghien-cuu-manh--10876.

Olmos-Peñuela J, Castro-Martínez E and D'Este P (2014) Knowledge transfer activities in social sciences and humanities: Explaining the interactions of research groups with non-academic agents. Research Policy 43(4): 696-706.

Price J H, Dake J A and Oden L (2000) Authorship of Health Education Articles: Guests, Ghosts, and Trends. American Journal of Health Behavior 24(4): 290-299.

Pham L T and Hayden M (2019) Research In Vietnam: The Experience Of The Humanities And Social Sciences. Journal of International and Comparative Education (JICE): 27-40\%@ 2232-1802.

Salmi J and Pham I T (2019) Academic Governance and Leadership in Vietnam: Trends and Challenges. Journal of International and Comparative Education (JICE): 103-118\%@ 2232-1802.

Tindall T and Hamil B (2004) Gender Disparity in Science Education: The Causes, Consequences, and Solutions. Education 125(2). 
Tran K (2019) 'Giải pháp tăng cường sự tham gia của phụ nữ trong lĩnh vực khoa học và công nghệ. [Solutions to enhance the participation of women in science and technology]. ', Tạp chí Tổ chức nhà nước. Available at: http://tcnn.vn/news/detail/45643/Giai-phap-tang-cuong-su-tham-giacua-phu-nu-trong-linh-vuc-khoa-hoc-va-cong-nghe.html

Tran T, Trinh P-T T, Vuong T-T and Pham H-H (2019) The debates and the long-awaited reform. In: Vuong, Q.-H. \& Tran, T. (eds) The Vietnamese Social Sciences at a Fork in the Road. De Gruyter: Warsaw, Poland, pp. 17-32.

Viglione G (2020) China is closing gap with United States on research spending. Nature.

VNS (2018a) 'Female scientists play key role in nation's sustainable development', Vietnam News. Available at: https://vietnamnews.vn/society/468147/female-scientists-plays-key-role-innations-sustainable-development.html

VNS (2018b) 'Việt Nam PhD holders produce little quality research', Vietname News. Available at: https://vietnamnews.vn/society/422948/viet-nam-phd-holders-produce-little-qualityresearch.html.

Vu T-H, Tran T, Hoang P-H and Nguyen M-H (2019) Economics: The trend-setting field. In: Vuong, Q.-H. \& Tran, T. (eds) The Vietnamese Social Sciences at a Fork in the Road. De Gruyter: Warsaw, Poland, pp. 80-97.

Vuong Q-H (2018) "How did researchers get it so wrong?" The acute problem of plagiarism in Vietnamese social sciences and humanities. European Science Editing 43(3): 56-58.

Vuong Q-H (2019a) Breaking barriers in publishing demands a proactive attitude. Nature Human Behaviour 3(10): 1034-1034.

Vuong Q-H (2019b) The harsh world of publishing in emerging regions and implications for editors and publishers: The case of Vietnam. Learned Publishing 32(4): 314-324.

Vuong Q-H, Ho M-T, Vuong T-T, Napier N K, Pham H-H and Nguyen V-H (2017) Gender, age, research experience, leading role and academic productivity of Vietnamese researchers in the social sciences and humanities: exploring a 2008-2017 Scopus dataset. European Science Editing 43(3): 51-55.

Vuong Q-H, La V-P, Vuong T-T, Ho M-T, Nguyen H-K T, Nguyen V-H, Pham H-H and Ho M-T (2018) An open database of productivity in Vietnam's social sciences and humanities for public use. Scientific Data 5: 180188.

Vuong Q-H, Napier N K, Ho T M, Nguyen V H, Vuong T-T, Pham H H and Nguyen H K T (2019) Effects of work environment and collaboration on research productivity in Vietnamese social sciences: evidence from 2008 to 2017 scopus data. Studies in Higher Education 44(12): 2132-2147.

Vuong Q H (2017) Open data, open review and open dialogue in making social sciences plausible. Scientific Data Updates. Available at: https://go.nature.com/2QdnUrW (Accessed: 28 Feb 2020).

Vuong Q H (2020) Plan S, self-publishing, and addressing unreasonable risks of society publishing. Learned Publishing 33(1): 64-68. 
Webster B M (1998) Polish Sociology Citation Index as an example of usage of national citation indexes in scientometric analysis of social sciences. Journal of information science 24(1): 19-32.

Wu S (2019) China: How science made a superpower. Nature 574 (7776): 25-28.

Yucha C (2015) Predatory publishing: What authors, reviewers, and editors need to know. Biological Research For Nursing 17(1): 5-7.

Zhou P, Thijs, B. \& Glänzel, W. (2009) Is China also becoming a giant in social sciences? Scientometrics 79: 593-621. 